\title{
A Corticotropin Releasing Factor Network in the Extended Amygdala for Anxiety
}

\author{
Matthew B. Pomrenze, ${ }^{1,2}$ - Jorge Tovar-Diaz, ${ }^{2}$ Angelo Blasio, ${ }^{-}$Rajani Maiya, ${ }^{2,3}$ Simone M. Giovanetti, ${ }^{2,3}$ (OKelly Lei, ${ }^{4}$ \\ (-Hitoshi Morikawa, ${ }^{1,2}$ F. Woodward Hopf, ${ }^{4}$ and $『$ Robert 0. Messing ${ }^{1,2,3}$ \\ ${ }^{1}$ Institute for Neuroscience, ${ }^{2}$ Department of Neuroscience, ${ }^{3}$ Department of Neurology, University of Texas at Austin, Austin, Texas 78712, \\ and ${ }^{4}$ Department of Neurology, University of California San Francisco, San Francisco, California 94158
}

The central amygdala (CeA) is important for fear responses to discrete cues. Recent findings indicate that the CeA also contributes to states of sustained apprehension that characterize anxiety, although little is known about the neural circuitry involved. The stress neuropeptide corticotropin releasing factor (CRF) is anxiogenic and is produced by subpopulations of neurons in the lateral CeA and the dorsolateral bed nucleus of the stria terminalis (dlBST). Here we investigated the function of these CRF neurons in stress-induced anxiety using chemogenetics in male rats that express Cre recombinase from a Crh promoter. Anxiety-like behavior was mediated by CRF projections from the CeA to the dlBST and depended on activation of CRF1 receptors and CRF neurons within the dlBST. Our findings identify a $\mathrm{CRF}^{\mathrm{CeA}} \rightarrow \mathrm{CRF}^{\mathrm{dlBST}}$ circuit for generating anxiety-like behavior and provide mechanistic support for recent human and primate data suggesting that the CeA and BST act together to generate states of anxiety.

Key words: amygdala; anxiety; bed nucleus of the stria terminals; chemogenetics; corticotropin releasing factor

\section{Significance Statement}

Anxiety is a negative emotional state critical to survival, but persistent, exaggerated apprehension causes substantial morbidity. Identifying brain regions and neurotransmitter systems that drive anxiety can help in developing effective treatment. Much evidence in rodents indicates that neurons in the bed nucleus of the stria terminalis (BST) generate anxiety-like behaviors, but more recent findings also implicate neurons of the CeA. The neuronal subpopulations and circuitry that generate anxiety are currently subjects of intense investigation. Here we show that CeA neurons that release the stress neuropeptide corticotropinreleasing factor (CRF) drive anxiety-like behaviors in rats via a pathway to dorsal BST that activates local BST CRF neurons. Thus, our findings identify a $\mathrm{CeA} \rightarrow \mathrm{BST} \mathrm{CRF}$ neuropeptide circuit that generates anxiety-like behavior.

\section{Introduction}

Threatening environments evoke fear and anxiety, which are two ethologically different defensive behavioral responses that are driven by conserved brain circuits and promote survival (Panksepp, 2011; LeDoux and Brown, 2017). Fear responses are acute and generated when animals are presented with an imminent threat or a cue that predicts the threat. In contrast, environments providing ambiguous or diffuse cues for threat prediction pro-

\section{Received Sept. 6, 2018; revised Oct. 24, 2018; accepted Dec. 1, 2018.}

Author contributions: M.B.P. wrote the first draft of the paper; M.B.P., J.T.-D., R.M., H.M., F.W.H., and R.O.M. edited the paper; M.B.P., H.M., F.W.H., and R.O.M. designed research; M.B.P., J.T.-D., A.B., R.M., S.M.G., K.L., and F.W.H. performed research; M.B.P., J.T.-D., H.M., F.W.H., and R.O.M. analyzed data; M.B.P. and R.O.M. wrote the paper.

This work was supported by National Institutes of Health Grants AA13588 and AA026075 to R.O.M. and Grant AA023223 to F.W.H., and National Science Foundation Graduate Research Fellowship DGE-1110007 to M.B.P.

The authors declare no competing financial interests.

Correspondence should be addressed to Robert 0. Messing at romessing@austin.utexas.edu.

https://doi.org/10.1523/JNEUROSCI.2143-18.2018

Copyright $\odot 2019$ the authors $\quad 0270-6474 / 19 / 391030-14 \$ 15.00 / 0$ mote a sustained state of avoidance, apprehension, and riskassessment (i.e., anxiety). Both of these behavioral profiles are adaptive and essential to survival, yet exaggerated and persistent fear and anxiety reactions can be maladaptive and hinder survival. Unfortunately, anxiety disorders are prevalent psychiatric conditions that cause substantial morbidity worldwide (Baxter et al., 2013).

The neuronal circuitry underlying fear has been extensively studied and the amygdala has emerged as a critical component. The circuits governing anxiety are less understood but were originally considered to be independent of the amygdala. An influential conceptual framework that emerged from early lesion and inactivation studies proposed that the central amygdala (CeA) mediates fear responses to discrete threats, while the bed nucleus of the stria terminalis (BST), a forebrain structure with strong connections to the amygdala (together referred to as the extended amygdala), mediates states of anxiety (Walker et al., 2003). However, with the advent of new tools allowing access to genetically defined neuronal populations, recent work has demonstrated the 
$\mathrm{CeA}$ as a potent driver of anxiety-like behavior in mice (Botta et al., 2015; McCall et al., 2015; Ahrens et al., 2018; Pliota et al., 2018).

A role for the neuropeptide corticotropin releasing factor (CRF) in anxiety has been suspected because of its control over neuroendocrine responses to stress (Bale and Vale, 2004; Koob, 2009; Binder and Nemeroff, 2010) and its high expression in the extended amygdala (Asan et al., 2005; Pomrenze et al., 2015; Nguyen et al., 2016; Sanford et al., 2017). In agreement with this hypothesis, CRF administration into the ventricles or the dorsolateral BST (dlBST) in rats generates anxiety-like behaviors (Swerdlow et al., 1986; Liang et al., 1992; Lee and Davis, 1997; Sahuque et al., 2006) that are reduced by CRF 1 receptor antagonists injected into the BST, but not into the CeA (Lee and Davis, 1997; Sahuque et al., 2006). Thus, the BST appears to orchestrate anxiety-like responses that are dependent on CRF.

The source of CRF that acts in the BST to generate anxiety is not certain. One possibility is the population of CRF neurons that reside within the BST. Another source could be CRF CeA $\left(\mathrm{CRF}^{\mathrm{CeA}}\right)$ neurons because activation of those neurons can produce anxiety-like behavior in mice (Regev et al., 2012; McCall et al., 2015; Pliota et al., 2018), and in rats the number of CRF-like immunoreacive fibers in the dlBST appeared reduced in animals with electrolytic lesions of the amygdala that included the CeA (Sakanaka et al., 1986). However, the density of $\mathrm{CRF}^{\mathrm{CeA}}$ projections to the BST has not been quantified, and its role in anxiety has not yet been demonstrated.

Here, we provide evidence in rats that stress-induced anxiety is critically dependent on $\mathrm{CRF}^{\mathrm{CeA}}$ projections to the dlBST and on activation of CRF1 receptors and CRF neurons in the dlBST. Our findings identify a circuit by which CRF neurons in the CeA and BST cooperate in series to generate anxiety. These results support recent human and primate data suggesting that the CeA and BST work together as a functional unit to generate anxiety (Gungor and Paré, 2016; Shackman and Fox, 2016).

\section{Materials and Methods}

Subjects. All experiments and procedures were approved by the University of Texas at Austin Institutional Animal Care and Use Committee and were performed in accordance with the guidelines described in the National Institutes of Health's Guide for the care and use of laboratory animals. We used male heterozygous Crh-Cre rats (Pomrenze et al., 2015) outcrossed to WT Wistar rats (Envigo), 5-6 weeks of age at the start of the surgical procedures and 10-14 weeks at the start of experimental procedures. Rats were group housed and maintained on a $12 \mathrm{~h} \mathrm{light/dark}$ cycle (lights on 4:00 A.M. to 4:00 P.M.) with food and water available ad libitum. Rats prepared with guide cannulas were singly housed. All experiments were done between 9:00 A.M. and 3:00 P.M. Rats were randomly assigned to either experimental or control groups within each litter.

Drugs and viral vectors. Clozapine- $\mathrm{N}$-oxide (CNO) was supplied through the National Institute of Mental Health Chemical Synthesis and Drug Supply Program. CNO ( $2 \mathrm{mg} / \mathrm{kg}$ body weight $)$ was dissolved in $5 \%$ DMSO and then diluted to $2 \mathrm{mg} / \mathrm{ml}$ with $0.9 \%$ saline. For intracerebral administration, $\mathrm{CNO}$ was dissolved in $0.5 \% \mathrm{DMSO}$ and then diluted to 1 mm in aCSF (Harvard Apparatus) (Mahler et al., 2014). The selective CRF1 receptor antagonist R121919 (3-(6-(dimethylamino)-4-methylpyrid-3-yl)-2,5-dimethyl- $N$, $N$-dipropyl-pyrazolo(2,3-a)pyrimidin-7amine, NBI 30775, was a gift from Dr. Kenner Rice (Chemical Biology Research Branch, Drug Design and Synthesis Section, National Institute on Drug Abuse and National Institute on Alcohol Abuse and Alcoholism, Rockville, MD) and dissolved in a 1:1 solution of $0.9 \%$ saline and $1 \mathrm{~N} \mathrm{HCl}$ before adding $25 \%$ hydroxypropyl- $\beta$-cyclodextrin to yield a final concentration of $10 \mathrm{mg} / \mathrm{ml} \mathrm{R} 121919$ in $20 \%$ hydroxypropyl- $\beta$-cyclodextrin, $\mathrm{pH}$ 4.5. For intracerebral infusion, R121919 was prepared in 4\% kolli- phor RH 40 in aCSF, pH 5. Salvinorin B (SalB; Apple Pharms) was dissolved in $100 \%$ DMSO at $15 \mathrm{mg} / \mathrm{ml}$, followed by $5 \mathrm{~min}$ of sonication. SalB was administered at $15 \mathrm{mg} / \mathrm{kg}$ body weight. All systemic injections were administered at $1 \mathrm{ml} / \mathrm{kg}$.

Cre-dependent adeno-associated viral vectors AAV8-hSyn-DIO-hM3DqmCherry, AAV8-hSyn-DIO-hM4Di-mCherry, AAV8-hSyn-DIO-mCherry, AAV5-EF1 $\alpha$-DIO-eYFP, AAV2-Ef1 $\alpha$-flex-taCaspase3-TEVp, and AAV9-hSyn-DIO-KORD-IRES-mCitrine were obtained from the University of North Carolina Viral Vector Core and were injected at $4-6 \times$ $10^{12}$ infectious units per milliliter. Canine adeno virus 2 (CAV2) carrying a flex-ZsGreen reporter expressed from the CAG promoter (CAV2CAG-flex-ZsGreen) was a gift from Dr. Larry Zweifel (University of Washington, Seattle) and was injected at $2 \times 10^{12}$ infectious units per milliliter.

Stereotaxic surgery. At the start of surgical procedures, rats were anesthetized with isoflurane $(5 \% \mathrm{v} / \mathrm{v})$ and placed in a stereotaxic frame (David Kopf Instruments). Viruses were injected into the CeA (anteroposterior: -2.1 ; mediolateral: \pm 4.5 ; dorsoventral: -8.0 from skull) or dlBST (anteroposterior: -0.0 ; mediolateral: \pm 3.5 ; dorsoventral: -6.8 from skull, $16^{\circ}$ angle) at a rate of $150 \mathrm{nl} / \mathrm{min}$ over $5 \mathrm{~min}(750-800 \mathrm{nl}$ total volume per hemisphere) with a custom 32-gauge injector cannula coupled to a pump-mounted $2 \mu \mathrm{l}$ Hamilton syringe. Injectors were slowly retracted after a $5 \mathrm{~min}$ diffusion period. Rats were 190-220 $\mathrm{g}$ at the time of viral injection. Virus-injected rats were group housed to recovery for 1-2 months before behavioral or histological examination.

Two to three months after viral injection, rats used for intracerebral targeting were bilaterally implanted with stainless steel guide cannulas (Plastics One) directed to the dlBST (anteroposterior: -0.2 ; mediolateral: \pm 3.55; dorsoventral: -5.1 from skull, $18^{\circ}$ angle; injector tips emerged $2 \mathrm{~mm}$ from the cannula tips). Cannulas were affixed to the skull with stainless-steel screws and dental acrylic (H00325, Coltene). Cannula-implanted rats were administered the antibiotic cefazolin (100 $\mathrm{mg} / \mathrm{kg}$, s.c.) and singly housed during a 1-2-week recovery period before experiments.

Immobilization stress (IMS). Rats were transferred to an experimental room distinct from the behavioral testing room and placed in ventilated plastic Decapicone bags (Braintree Scientific) for $30 \mathrm{~min}$. Each rat was monitored every 5 min to ensure sufficient immobilization and respiration rate. Rats were tested for anxiety-like behavior $10 \mathrm{~min}$ later. Some rats received injections of the CRF1 receptor antagonist R121919 (20 $\mathrm{mg} / \mathrm{kg}$, s.c.) $60 \mathrm{~min}$ before stress. Separate groups of rats received CNO (2 $\mathrm{mg} / \mathrm{kg}$, i.p.) $60 \mathrm{~min}$ before stress, or $1 \mathrm{~mm}$ in $0.3 \mu \mathrm{l}(300 \mathrm{pmol})$ via cannula 5 min before stress.

Behavior. We used three assays to evaluate anxiety-like behavior: the elevated plus maze (EPM), the open field test (OF) and the social interaction test. We conducted these assays as a test battery on the same group of rats. Usually just a few minutes elapsed between each test. Only when we injected CNO systemically in the absence of stress was there an interval of 3-5 d between testing in the EPM and OF. Anxiety testing occurred in a room that was different from the one used to immobilize and administer drugs. The EPM consisted of two open arms $(50 \times 10 \mathrm{~cm})$ and two enclosed arms $(50 \times 10 \times 40 \mathrm{~cm})$ connected by a central area measuring $10 \times 10 \mathrm{~cm}, 50 \mathrm{~cm}$ above the floor. At the beginning of each trial, rats were placed in the center facing one open arm. Trials lasted for $6 \mathrm{~min}$ and were performed under red lighting to promote exploration. The OF consisted of an open topped arena $(100 \times 100 \times 50 \mathrm{~cm})$ situated on the floor. The center area was designated as a central zone measuring $55 \times 55 \mathrm{~cm}$. Rats were placed into a corner of the arena at the beginning of each trial. Each test lasted for $10 \mathrm{~min}$ and was performed under red lighting to promote exploration of the center. Social interaction was measured by placing a novel juvenile rat ( $4-5$ weeks) into a $70 \times 70 \mathrm{~cm}$ arena and then placing an experimental adult rat into the arena. The adult rat was allowed to interact with the juvenile rat for $5 \mathrm{~min}$ under red lighting. Exploratory behaviors, such as allogrooming, sniffing, and pinning initiated by the adult rat, were considered interactions (Christianson et al., 2010). All testing equipment was cleaned with $70 \%$ ethanol between trials. Behaviors were tracked with EthoVision (Noldus Information Technology). 
Chemogenetic manipulations. Crh-Cre rats were microinjected bilaterally in the CeA with AAV8-hSyn-DIO-hM3Dq-mCherry, AAV8-hSynDIO-hM4Di-mCherry, or AAV8-hSyn-DIO-mCherry. After 4-6 weeks of recovery, rats were injected with $\mathrm{CNO}(2 \mathrm{mg} / \mathrm{kg}$, i.p. $)$ and subjected to immobilization stress and behavioral tests at times indicated. To manipulate $\mathrm{CRF}^{\mathrm{CeA}}$ projections to dlBST, we bilaterally injected AAV8hSyn-DIO-hM4Di-mCherry, AAV8-hSyn-DIO-hM3Dq-mCherry, or AAV8-hSyn-DIO-mCherry into the CeA and after 8-10 weeks implanted bilateral guide cannulas directed at the dlBST. After 1-2 weeks of recovery, we administered $\mathrm{CNO}(1 \mathrm{~mm}$ in $0.3 \mu \mathrm{l})$ through the BST cannulas before immobilization stress and behavioral testing. To inhibit CRF1 receptors, we administered R121919 systemically at $20 \mathrm{mg} / \mathrm{kg}$ s.c., $30 \mathrm{~min}$ before administering $\mathrm{CNO}$, or into the dlBST at $1 \mu \mathrm{g}$ in $0.3 \mu \mathrm{l}, 5$ min before injecting CNO.

To investigate the interdependence of CeA and dlBST CRF neurons, we unilaterally injected AAV8-hSyn-DIO-hM3Dq-mCherry into the CeA and AAV9-hSyn-DIO-KORD-IRES-mCitrine that expresses the inhibitory $\kappa$ opioid receptor designer receptor exclusively activated by designer drugs (DREADD) into the ipsilateral dlBST, counterbalanced with respect to the injected hemisphere. After a 4-6-week recovery rats were administered CNO (2 mg/kg, i.p.), SalB (15 mg/kg, s.c.) or CNO plus $\mathrm{SalB}$, and tested for anxiety-like behavior $15 \mathrm{~min}$ later.

CRF circuit disconnection. Rats were unilaterally injected with a 1:2 ratio of AAV5-EF1 $\alpha$-DIO-eYFP and AAV2-Ef1 $\alpha$-flex-taCasp3-TEVp into the CeA and the contralateral dlBST. Control rats were injected with eYFP + taCasp3 into the CeA of one side and eYFP+PBS into the contralateral dlBST. Additional controls received eYFP + taCasp 3 in the dlBST of one side and eYFP+PBS into the contralateral CeA. A final group was injected with eYFP + taCasp3 into the CeA, and the ipsilateral dlBST. eYFP was diluted (1:2) in sterile PBS for controls so an equivalent volume of eYFP was injected into the CeA and dlBST in all animals. All injections were counterbalanced with respect to injected hemispheres. Similar viral injection parameters were used for bilateral CeA injection (controls received eYFP+PBS). After 4-6 weeks of recovery, rats were subjected to IMS and tested for anxietylike behavior.

Brain slice electrophysiology. Rats were injected with AAV-hSyn-DIOhM4Di-mCherry or AAV-hSyn-DIO-hM3Dq-mCherry into the CeA. After 2-3 months, rats were anesthetized with pentobarbital (100 mg/kg) and decapitated, and brain slices containing the CeA were cut in an ice-cold glycerol-based solution (in mM as follows: 252 glycerol, $2.5 \mathrm{KCl}$, $1.25 \mathrm{NaH}_{2} \mathrm{PO}_{4}, 1 \mathrm{MgCl}_{2}, 2 \mathrm{CaCl}_{2}, 25 \mathrm{NaHCO}_{3}, 1$ L-ascorbate, and 11 glucose, bubbled with carbogen). Slices recovered at $32^{\circ} \mathrm{C}$ in carbogenbubbled aCSF (containing the following in mM: $126 \mathrm{NaCl}, 2.5 \mathrm{KCl}, 1.2$ $\mathrm{NaH}_{2} \mathrm{PO}_{4}, 1.2 \mathrm{MgCl}_{2}, 2.4 \mathrm{CaCl}_{2}, 18 \mathrm{NaHCO}_{3}, 11$ glucose, pH 7.2-7.4, mOsm 302-305) for at least $30 \mathrm{~min}$ before experiments, with $1 \mathrm{~mm}$ ascorbic acid added just before the first slice. During experiments, slices were submerged and perfused $(2 \mathrm{ml} / \mathrm{min})$ with aCSF at $31^{\circ} \mathrm{C}-32^{\circ} \mathrm{C}$. $\mathrm{CNO}$-related changes in firing or membrane potential were recorded in current-clamp mode using Clampex 10.1 and an Axon Multiclamp 700A patch amplifier (Molecular Devices). All experiments used whole-cell recording with infrared-DIC visualization and 2.5-3.5 $\mathrm{m}$ electrodes that were filled with a potassium-methanesulfonate-based internal solution (in $\mathrm{mm}$ as follows: $130 \mathrm{KOH}, 105$ methanesulfonic acid, $17 \mathrm{HCl}, 20$ HEPES, 0.2 EGTA, $2.8 \mathrm{NaCl}, 2.5 \mathrm{mg} / \mathrm{ml} \mathrm{Mg-ATP,} 0.25 \mathrm{mg} / \mathrm{ml} \mathrm{GTP,} \mathrm{pH}$ 7.2-7.4, 278-287 mOsm).

Corticosterone measurement. Rats were microinjected with AAV8hSyn-DIO-hM4Di-mCherry into the CeA. After recovery, rats were injected with $\mathrm{CNO}(2 \mathrm{mg} / \mathrm{kg}$, i.p.) or vehicle and $60 \mathrm{~min}$ later immobilized for $30 \mathrm{~min}$. Rats were then immediately killed for trunk blood collection. Blood corticosterone concentrations were measured using an enzyme immunoassay kit (900-097, Enzo Life Sciences).

Histology. All rats were checked for virus expression and implanted cannula locations after behavioral studies were completed. For immunofluorescence, rats were anesthetized with isoflurane and perfused transcardially with $1 \times$ PBS followed by $4 \%$ PFA in PBS, pH 7.4. Brains were extracted, allowed to postfix overnight in the same fixative, and cryoprotected in $30 \%$ sucrose in PBS at $4^{\circ} \mathrm{C}$. Each brain was sectioned at $40 \mu \mathrm{m}$ on a cryostat (Thermo Fisher Scientific) and collected in PBS. Staining for injected viruses (except KORD-IRES-mCitrine) was omitted due to strong native fluorescence.

For immunohistochemistry, free-floating sections were washed three times in PBS with $0.2 \%$ Triton X-100 (PBST) for $10 \mathrm{~min}$ at room temperature. Sections were then incubated in blocking solution made of PBST with 3\% normal donkey serum (Jackson ImmunoResearch Laboratories, \#017-000-121) for $1 \mathrm{~h}$. Sections were next incubated in primary antibodies goat anti-CRF (1:1000, Santa Cruz Biotechnology, sc1761, Lot \#B0315, RRID:AB_631299), rabbit anti-GFP (1:1000, Abcam, ab290, lot \#GR135929-1, RRID:AB_303395) or rabbit anti-PKC $\delta$ (1:2000, Santa Cruz Biotechnology, sc-213, lot \#D2210, RRID:AB_632228) in blocking solution rotating at $4^{\circ} \mathrm{C}$ for $18-20 \mathrm{~h}$. After three 10 min washes in PBST, sections were incubated in species-specific secondary antibodies AlexaFluor-488, -594, or -647 (1:700, Invitrogen, A-21206, A-11055, A-21208, A11073, A-21447, A-31573) in blocking solution for $1 \mathrm{~h}$ at room temperature. Finally, sections were washed three times for $10 \mathrm{~min}$ in $1 \times$ PBS. Sections were then mounted in $0.2 \%$ gelatin water onto SuperFrost Plus glass slides (Fisherbrand, 12-550-15), coverslipped with Fluoromount-G with DAPI (Southern Biotechnology, 0100-20), and stored in the dark. Fluorescent images were collected on a Carl Zeiss 710 LSM confocal microscope or a Carl Zeiss Axio Zoom stereo microscope. Quantification of fluorescence was performed on 3-6 sections per rat from 5 rats spanning the rostral-caudal axis of the CeA (from approximately bregma -1.90 to -3.00 ) using the cell-counter plugin in Fiji (Schindelin et al., 2012).

FISH. For examination of gene expression in the dlBST, coronal sections were processed for FISH by RNAscope according to the manufacturer's guidelines. Genes examined in the dlBST were Crh (ACDBio catalog \#318931) and proEnkephalin (ACDBio catalog \#417431) and hybridization was performed using RNAscope Fluorescent Multiplex Kit (Advanced Cell Diagnostics). Slides were coverslipped with Fluoromount-G with DAPI (Southern Biotechnology, 0100-20) and stored at $4^{\circ} \mathrm{C}$ in the dark before imaging.

Experimental design and statistical analysis. We calculated sample sizes of $n=8-12$ animals per condition using SD values measured in pilot studies of IMS-induced anxiety-like behavior, $\alpha=0.05$, and power $=$ 0.80 , with the goal of detecting a $25 \%-35 \%$ difference in mean values for treated and control samples, using the program $G^{\star}$ Power (Faul et al., 2007). Studies were performed with the experimenter blind to the identity of the drugs that were administered, except in which CRF1 receptors in the dlBST were inhibited during activation of CRF ${ }^{\mathrm{CeA}}$ terminals in the dlBST. In those experiments, the results were analyzed as coded group values by a blinded investigator who also reviewed cannulation and injection placement images blind and removed 2 animals from the analysis because of cannula misplacement. All results were expressed as mean \pm SEM values and analyzed using Prism 7 (GraphPad Software). Data distribution and variance were tested using Shapiro-Wilk normality tests. Normally distributed data were analyzed by unpaired, two-tailed $t$ tests, or one or two factor ANOVA with post hoc Tukey's or Bonferroni's multiple-comparisons tests. In one case, where only one direction of change was expected, we used a one-tailed $t$ test (percentage of total distance in the center of the OF in WT rats treated with R121919). Data that were not normally distributed were analyzed by Mann-Whitney $\mathrm{U}$ tests when comparing two conditions, or were transformed to square root values, as noted, before performing a two-factor ANOVA. Differences were considered significant when $p<0.05$.

\section{Results \\ $\mathrm{CRF}^{\mathrm{CeA}}$ neurons contribute to stress-induced anxiety}

To evoke anxiety, we subjected Wistar rats to $30 \mathrm{~min}$ of IMS, which is a commonly used procedure that reliably increases anxiety-like behavior (Paré and Glavin, 1986; Buynitsky and Mostofsky, 2009) through a process mediated by CRF (Regev et al., 2012). We measured subsequent behavior in the EPM and OF, which are commonly used to assess anxiety-like behavior in rodents. IMS reduced the percentage of time spent on the open arms (No IMS: $19.23 \pm 2.9$, IMS: $7.83 \pm 2.03 ; t_{(13)}=3.28,{ }^{* *} p=$ 0.006 , unpaired $t$ test) and percentage of open arm entries (No 
IMS: $34.35 \pm 1.9$, IMS: $12.59 \pm 2.8 ; t_{(13)}=6.164,{ }^{* * * *} p<0.0001$, unpaired $t$ test) on the EPM without affecting closed arm entries (No IMS: $13.29 \pm 0.36$, IMS: $13.0 \pm 0.73 ; t_{(13)}=0.3344, p=$ 0.7434 , unpaired $t$ test, $n=7$ no IMS, 8 IMS). IMS also reduced the time spent in the center of the OF (No IMS: $67.03 \pm 10.4 \mathrm{~s}$, IMS: $12.55 \pm 3.7 \mathrm{~s} ; t_{(13)}=5.19,{ }^{* * *} p=0.0002 ; n=7$ control, 8 IMS, unpaired $t$ test). Although IMS also reduced the total distance traveled in the OF (No IMS: $6710 \pm 353 \mathrm{~cm}$, IMS: $4176 \pm$ $391 \mathrm{~cm} ; t_{(13)}=4.749,{ }^{* *} p=0.0004$, unpaired $t$ test), the percentage of total distance traveled in the center of the OF was significantly lower in stressed rats (No IMS: $13.76 \pm 2.3$, IMS: $4.05 \pm 1.3 ; t_{(13)}=3.791,{ }^{* *} p=0.0022$, unpaired $t$ test $)$. Consistent with a role for CRF in stress-induced anxiety, systemic administration of a selective CRF1 receptor antagonist, R121919 (Chen et al., 2004) (20 mg/kg, s.c., administered 1 h before IMS), prevented the IMS-induced reduction in percentages of open arm time (Vehicle: $11.25 \pm 1.7, \mathrm{R} 12: 23.58 \pm 2.2 ; t_{(20)}=4.324$, ${ }^{* * *} p=0.0003$, unpaired $t$ test) and entries (Vehicle: $17.36 \pm 2.2$, $\mathrm{R} 12: 35.55 \pm 1.1 ; t_{(20)}=7.280,{ }^{* * *} p<0.0001$, unpaired $t$ test) without affecting the number of closed arm entries on the EPM (Vehicle: $12.0 \pm 0.38, \mathrm{R} 12: 11.0 \pm 0.49 ; t_{(20)}=1.618, p=0.1213$, unpaired $t$ test, $n=11$ both groups). R121919 also prevented IMS-induced reductions in the time spent (Vehicle median: $6.1 \mathrm{~s}$, R12 median: $23.1 \mathrm{~s} ; U=29,{ }^{\star} p=0.04$, Mann-Whitney test) and percentage of distance traveled (Vehicle: $2.93 \pm 0.62, \mathrm{R} 12: 5.01 \pm$ $0.79 ; t_{(20)}=2.072,{ }^{*} p=0.0275$, unpaired $t$ test) in the center of the OF without altering the total distance traveled (Vehicle: $3917 \pm 283 \mathrm{~cm}, \mathrm{R} 12: 4124 \pm 284 \mathrm{~cm} ; t_{(20)}=0.5164, p=0.6112$, unpaired $t$ test, $n=11$ both groups).

One central question is whether $\mathrm{CRF}^{\mathrm{CeA}}$ neurons mediate anxiety-like behavior in the rat like they do in the mouse (Regev et al., 2012; McCall et al., 2015; Pliota et al., 2018). To manipulate neuronal activity, we used BAC transgenic Crh-Cre Wistar rats, which express Cre recombinase in the CeA and in the dorsal BST under control of the Crh promoter (Pomrenze et al., 2015). We bilaterally transduced $\mathrm{CRF}^{\mathrm{CeA}}$ neurons (Fig. $1 A$ ) with an AAV encoding a Cre-dependent inhibitory hM4Di designer receptor with an mCherry reporter (Sternson and Roth, 2014). In Crh-Cre rats, nearly all CeA neurons expressing Cre recombinase produce CRF (Pomrenze et al., 2015). In acute brain slices, cells expressing hM4Di displayed hyperpolarization (Fig. $1 B$ ) when treated with the designer receptor agonist $\mathrm{CNO}\left(F_{(2,12)}=111.9, p<0.0001\right.$, one-way ANOVA; $n=4-6$ cells per condition, 10 rats total; ${ }^{* * * *} p<0.0001$ compared with control [no-DREADD] cells by Dunnett's test). CNO ( $2 \mathrm{mg} / \mathrm{kg}$, i.p. 1 h before IMS) also reduced anxiety-like behavior in rats expressing hM4Di compared with control animals expressing mCherry (Fig. $1 C-E)$. CNO increased the percentage of open arm time $\left(t_{(20)}=4.273,{ }^{* * *} p=0.004\right.$, unpaired $t$ test) and the percentage of open arm entries on the $\operatorname{EPM}\left(t_{(20)}=7.610,{ }^{* * *} p<0.0001\right.$, unpaired $t$ test $)$ without changing the number of closed arm entries $\left(t_{(20)}=1.312 ; p=\right.$ 0.2044 , unpaired $t$ test, $n=9 \mathrm{mCh}, 13 \mathrm{hM} 4 \mathrm{Di}$; Fig. $1 C)$. CNO also increased the time spent $\left(t_{(14)}=2.354,{ }^{\star} p=0.037\right.$, unpaired $t$ test) and distance traveled in the center of the $\mathrm{OF}\left(t_{(14)}=2.923\right.$, ${ }^{*} p=0.0111$, unpaired $t$ test) without altering the total distance traveled $\left(t_{(14)}=0.1652, p=0.8711\right.$, unpaired $t$ test, $n=8$ each group; Fig. $1 D)$. In addition, $\mathrm{CNO}$ increased social interaction time $\left(t_{(14)}=2.923,{ }^{* *} p=0.01\right.$, unpaired $t$ test, $n=9$ each group; Fig. $1 E$ ) in rats that expressed hM4Di compared with control rats that expressed mCherry $(\mathrm{mCh})$ in $\mathrm{CRF}^{\mathrm{CeA}}$ neurons.

To further explore the role of $\mathrm{CRF}^{\mathrm{CeA}}$ neurons in anxiety-like behavior, we used a different approach in which we genetically ablated neurons with a Cre-dependent caspase3 (Fig. 2) (Yang et al., 2013) instead of inhibiting them with activation of hM4Di. Bilateral caspase3-mediated ablation of $\mathrm{CRF}^{\mathrm{CeA}}$ neurons increased the percentage of open arm time $\left(U=7,{ }^{* *} p=0.0070\right.$, Mann-Whitney test) and the percentage of open arm entries in the $\operatorname{EPM}\left(t_{(14)}=3.909,{ }^{* *} p=0.0016\right.$, Mann-Whitney test $)$ without affecting the number of closed arm entries $\left(t_{(14)}=0.6754\right.$, $p=0.5104$, unpaired $t$ test; $n=8$, both groups; Fig. $2 A)$. Caspase3-mediated ablation also increased the time spent $(U=$ $7,{ }^{\star} p=0.0126$, Mann-Whitney test, $n=7$ eYFP, 8 Caspase) and the percentage of total distance traveled in the center of the OF $\left(U=6,{ }^{* *} p=0.0084\right.$, Mann-Whitney test, $n=7$ eYFP, 8 Caspase; Fig. $2 B$ ) without altering the total distance traveled $\left(t_{(13)}=1.415, p=0.1807\right.$, unpaired $t$ test; $n=7$ eYFP, 8 Caspase; Fig. $2 B$ ). These results indicate that genetic ablation of $\mathrm{CRF}^{\mathrm{CeA}}$ neurons, similar to DREADD inhibition, reduces IMS-induced anxiety-like behavior.

The CeA regulates hypothalamic-pituitary-adrenal axis activity via its projections to the brainstem (Schwaber et al., 1982; van der Kooy et al., 1984). To determine whether $\mathrm{CRF}^{\mathrm{CeA}}$ neurons affect stress-induced activation of the hypothalamic-pituitaryadrenal axis, we examined circulating corticosterone levels. Inhibiting hM4Di-expressing $\mathrm{CRF}^{\mathrm{CeA}}$ neurons with $\mathrm{CNO}$ did not affect circulating corticosterone levels in stressed rats (Vehicle: $766.9 \pm 46.9 \mathrm{ng} / \mathrm{ml}, \mathrm{CNO}: 849.5 \pm 84.4 \mathrm{ng} / \mathrm{ml} ; t_{(7)}=0.9061, p=$ 0.395 , unpaired $t$ test, $n=5$ Control, 4 CNO). This result indicates that $\mathrm{CRF}^{\mathrm{CeA}}$ neurons mediated stress-induced anxiety-like behavior independent of the hypothalamic-pituitary-adrenal axis.

Because activity of $\mathrm{CRF}^{\mathrm{CeA}}$ neurons was required for stressinduced anxiety, we next investigated whether activating $\mathrm{CRF}^{\mathrm{CeA}}$ neurons is sufficient to induce anxiety-like behavior, and whether inhibiting $\mathrm{CRF}^{\mathrm{CeA}}$ neurons reduces baseline anxiety-like behavior in the absence of stress. We injected the CeA of Crh-Cre rats with AAVs encoding Cre-dependent excitatory (hM3Dq) or inhibitory (hM4Di) designer receptors fused to an mCherry reporter, or an mCherry control (Fig. $1 A$ ). In CeA slices, cells expressing $\mathrm{hM} 3 \mathrm{Dq}$ displayed depolarization and spontaneous firing when treated with $\mathrm{CNO}$ (Fig. $1 B)$. CNO (2 mg/kg, i.p.) evoked anxiety-like behavior in rats expressing hM3Dq in $\mathrm{CRF}^{\mathrm{CeA}}$ cells but had no effect in rats that expressed hM4Di or mCherry alone (Fig. $1 F, G)$. In rats that expressed hM3Dq, CNO reduced the percentage of time spent on the open arms $\left(F_{(2,26)}=8.061\right.$, $p=0.0019$, one-way ANOVA, ${ }^{* *} p=0.0013$ compared with mCherry [mCh] by Dunnett's test) and the percentage of open arm entries on the $\operatorname{EPM}\left(F_{(2,26)}=23.75, p<0.0001\right.$, one-way ANOVA, ${ }^{* * *} p<0.0001$ compared with $\mathrm{mCh}$ by Dunnett's test) without affecting the number of closed arm entries $\left(F_{(2,26)}=\right.$ 2.982, $p=0.0682$, one-way ANOVA, $n=12 \mathrm{mCh}, 8$ hM4Di, 9 hM3Dq; Fig. $1 F$ ). Activation of hM3Dq with $\mathrm{CNO}$ reduced the time spent in the center of the $\mathrm{OF}\left(F_{(2,23)}=6.205, p=0.007\right.$, one-way ANOVA, ${ }^{* *} p=0.0091$ compared with mCherry by Dunnett's test) and tended to reduce the distance traveled in the center $\left(F_{(2,23)}=1.973, p=0.1618\right.$, one-way ANOVA, $n=9 \mathrm{mCh}$, 10 hM4Di, 7 hM3Dq; Fig. $1 G)$. The total distance traveled in the OF was unaffected by hM3Dq activation $\left(F_{(2,23)}=0.4411, p=\right.$ 0.6487, one-way ANOVA; Fig. $1 G$ ).

These findings demonstrate that activation of $\mathrm{CRF}^{\mathrm{CeA}}$ neurons was sufficient to increase anxiety-like behavior in nonstressed rats, but inhibition of these neurons did not alter baseline anxiety-like behavior, suggesting that $\mathrm{CRF}^{\mathrm{CeA}}$ neurons act specifically under conditions of stress. These findings also indicate that $\mathrm{CNO}$ induction of anxiety-like behavior in rats expressing hM3Dq was specific for activation of the hM3Dq DREADD and 


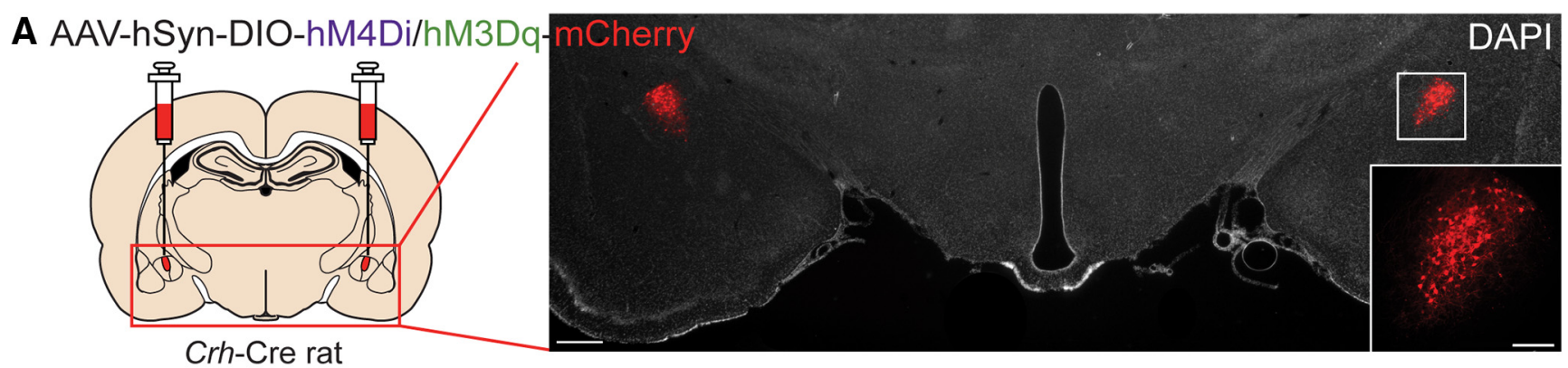

B

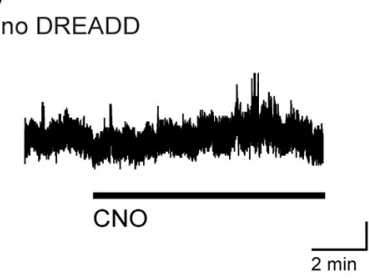

hM4Di
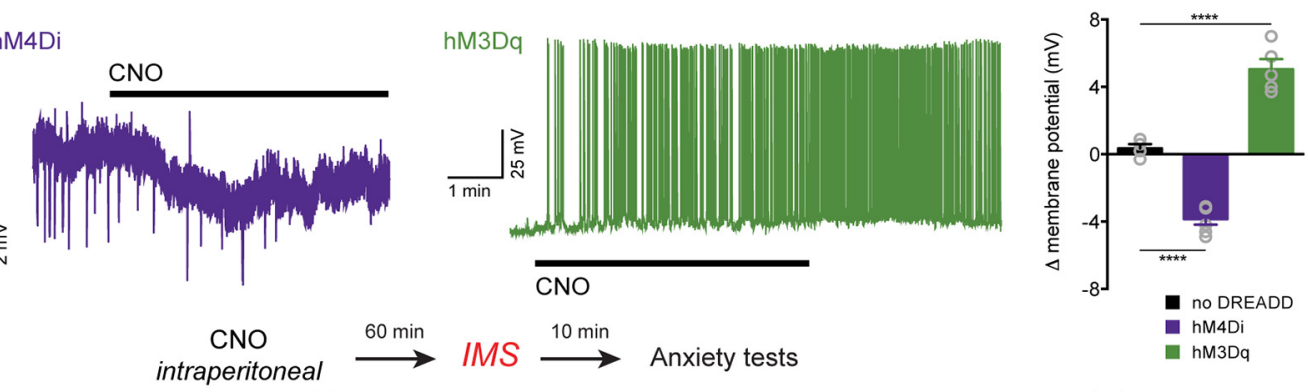

C

$\underset{\text { intraperitoneal }}{\mathrm{CNO}} \stackrel{60 \mathrm{~min}}{\longrightarrow} \mathrm{IMS} \stackrel{10 \mathrm{~min}}{\longrightarrow}$ Anxiety tests

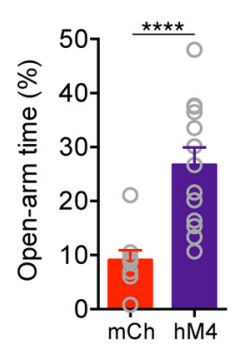

$\mathbf{F}$

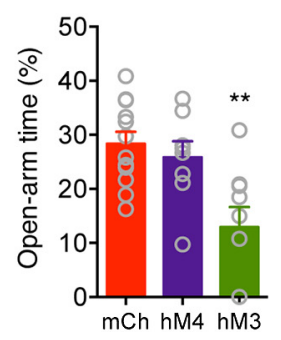

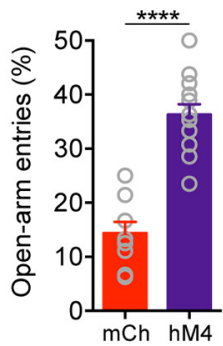

$\mathrm{mCh}$ hM4

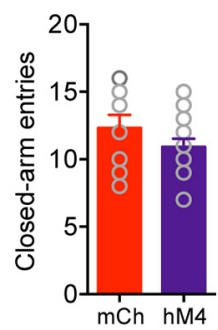

D

E
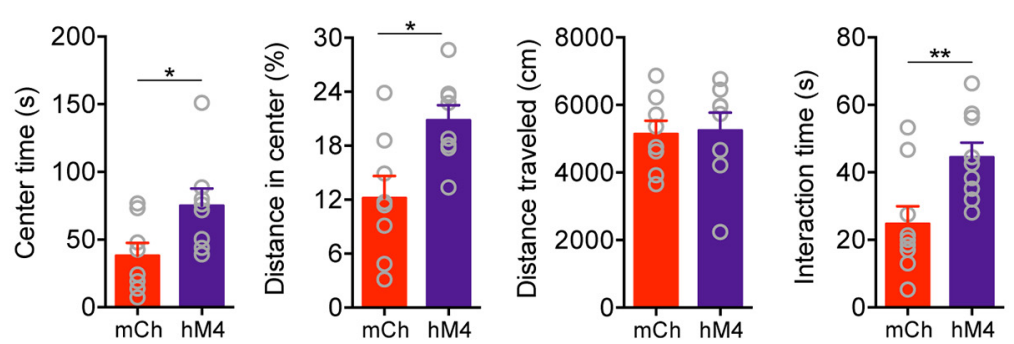

$\stackrel{\mathrm{CNO}}{\text { intraperitoneal }} \underset{\mathbf{G}}{\stackrel{60 \mathrm{~min}}{\longrightarrow}}$ Anxiety tests
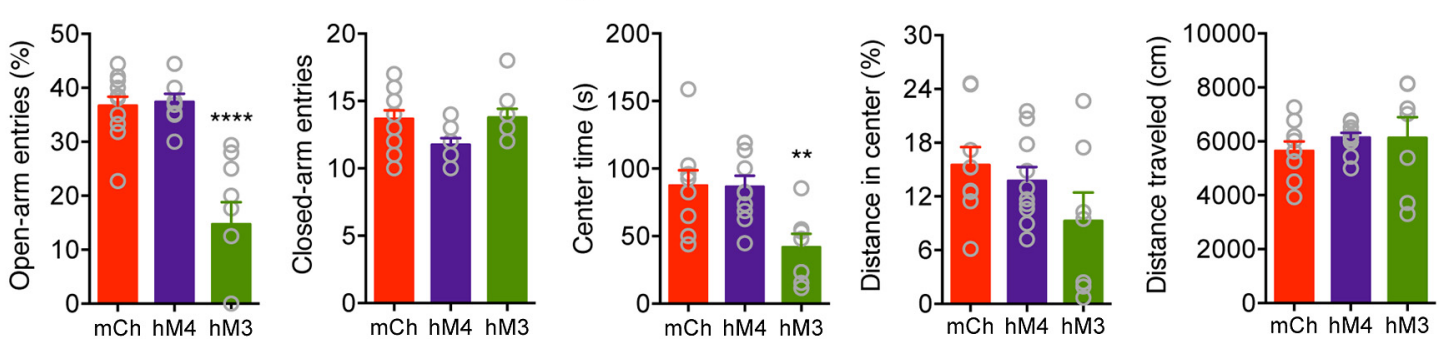

Figure 1. $\quad \mathrm{CRF}^{\mathrm{CeA}}$ neurons contribute to stress-induced anxiety. A, Injection schematic and image of AAV-DREADD-mCherry expression in CRF ${ }^{\mathrm{CeA}}$ neurons. Scale bar, $500 \mu \mathrm{m}$. Boxed region is enlarged in inset. Scale bar, $200 \mu \mathrm{m}$. B, Representative traces showing that bath application of CNO $(2 \mu \mathrm{M})$ had no effect in a neuron not expressing a DREADD (left), induced hyperpolarization of a neuron expressing DI0-hM4Di (middle), and promoted depolarization and spontaneous firing in a neuron expressing DI0-hM3Dq (right). Far right, Quantification of changes in resting membrane potential in CeA neurons during CNO application. C, CNO (2 mg/kg, i.p.) increased the percentage of time spent in the open arms of the EPM and the percentage of open arm entries without changing the number of closed arm entries. D, Activation of hM4Di with CNO increased the time spent in the center and the distance traveled in the center of the $0 \mathrm{~F}$ but did not alter the total distance traveled. $\boldsymbol{E}$, CNO also increased social interaction time in rats that expressed hM4Di compared with control rats that expressed mCherry in $\mathrm{CRF}^{\mathrm{CeA}}$ neurons. $F$, In rats that expressed hM3Dq in CRF ${ }^{\mathrm{CeA}}$ neurons, CNO $(2 \mathrm{mg} / \mathrm{kg}$, i.p.) reduced the percentage of time spent on the open arms of the EPM and reduced the percentage of open arm entries without affecting the number of closed arm entries. $G$, hM3Dq reduced the time spent in the center of the $\mathrm{OF}$ and marginally reduced the distance traveled in the center of the $0 \mathrm{~F}$ without affecting the total distance traveled. In contrast, activation of $\mathrm{hM} 4 \mathrm{Di}$ had no effect on anxiety-like behavior when compared with $\mathrm{mCh}$ control animals. Data are mean $\pm \mathrm{SEM} .{ }^{*} p<0.05,{ }^{* *} p<0.01,{ }^{* * * *} p<0.0001 . \mathrm{mCh}(\mathrm{mCherry}), \mathrm{hM} 4(\mathrm{hM} 4 \mathrm{Di}), \mathrm{hM} 3(\mathrm{hM} 3 \mathrm{Dq})$.

not due to an off-target effect of $\mathrm{CNO}$ or its metabolite clozapine (Gomez et al., 2017).

$\mathrm{CRF}^{\mathrm{CeA}}$ projections to the dlBST mediate anxiety

If the CRF that mediates stress-induced anxiety originates in the CeA and signals in the $\mathrm{BST}$, then $\mathrm{CRF}^{\mathrm{CeA}}$ projections should be present in the BST. Using an AAV to express Credependent mCherry (Fig. $3 A$ ), we identified $\mathrm{CRF}^{\mathrm{CeA}}$ fibers in the dorsolateral oval nucleus of the BST on the same side (Fig.
$3 A, B)$. Importantly, $\mathrm{CRF}^{\mathrm{CeA}}$ axons were clustered in a region of the dlBST in which local CRF ${ }^{\text {dlBST }}$ neurons were concentrated (Fig. $3 B$ ), along with $\mathrm{PKC} \delta$ - or enkephalin-expressing cells, which are distinct from CRF neurons (Fig. $3 F-H$ ). In addition, injection of the retrograde tracer canine adenovirus (CAV2) encoding flex-ZsGreen into the dlBST (Fig. 3C) labeled $46.1 \%$ of $1465 \mathrm{CRF}^{\mathrm{CeA}}$ neurons spanning the entire rostral-caudal axis of the CeA (Fig. $3 D, E$ ), indicating that approximately half of $\mathrm{CRF}^{\mathrm{CeA}}$ neurons project to and have 
A

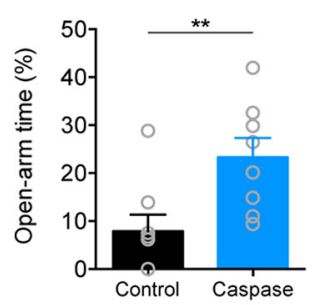

B

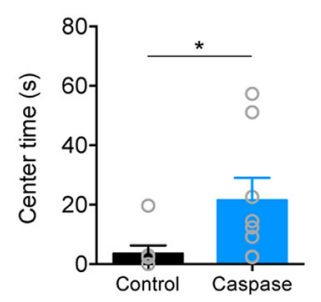

Casp3

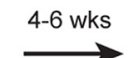

IMS

$\stackrel{10 \mathrm{~min}}{\longrightarrow}$

Anxiety tests
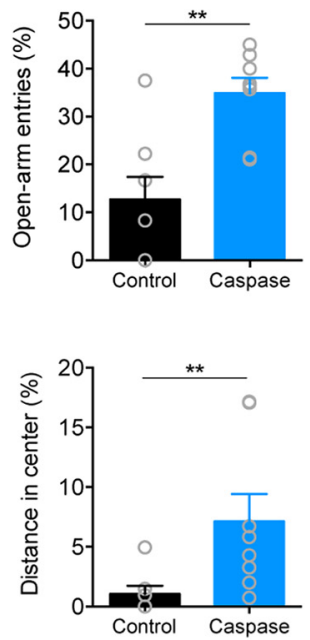
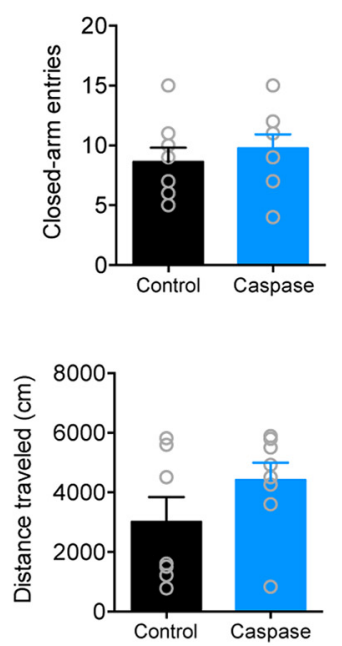

C
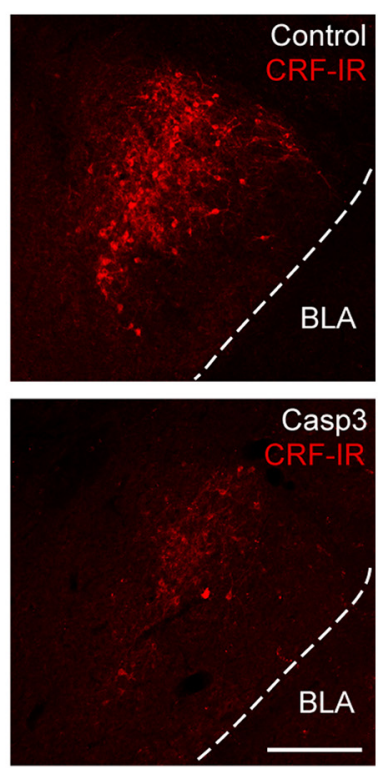

Figure 2. Genetic ablation of $\mathrm{CRF}^{\mathrm{CeA}}$ neurons prevents stress-induced anxiety. $\boldsymbol{A}$, Top, Experimental protocol. Bottom, Bilateral caspase3-mediated ablation of CRF ${ }^{\text {CeA }}$ neurons increased the percentage of time spent on the open arms and percentage of open arm entries during the EPM test without affecting the number of closed arm entries. $\boldsymbol{B}$, Time spent and the percentage of total distance traveled in the center of the OF were also increased without altering the total distance traveled. C, Example of CRF immunoreactivity in the CeA of control animal microinjected with eYFP+PBS (top) versus animal microinjected with eYFP+Caspase3 (bottom). Scale bar, $200 \mu \mathrm{m}$. Data are mean \pm SEM. ${ }^{*} p<0.05$, ${ }^{* *} p<0.01$. Casp3 (caspase3), BLA (basolateral amygdala), CRF-IR (CRF immunoreactivity).

terminals within the dlBST. There was no labeling of contralateral CeA neurons.

Because CRF ${ }^{\mathrm{CeA}}$ neurons projected to a region of the dlBST containing CRF neurons, we next investigated whether $\mathrm{CRF}^{\mathrm{CeA}}$ projections within the dlBST are important for stress-induced anxiety. We expressed hM4Di in $\mathrm{CRF}^{\mathrm{CeA}}$ neurons and targeted guide cannulas to the dlBST for delivery of CNO (Fig. 4A). We used a dose of CNO ( $1 \mathrm{~mm}$ in $0.3 \mu \mathrm{l} ; 300 \mathrm{pmol}$ ) previously reported to be effective in activating DREADDs in nerve terminals (Mahler et al., 2014). In Crh-Cre rats that expressed hM4Di in $\mathrm{CRF}^{\mathrm{CeA}}$ neurons, silencing $\mathrm{CRF}^{\mathrm{CeA}}$ terminals in the dlBST with $\mathrm{CNO}$ at this dose suppressed IMS-induced anxiety-like behavior (Fig. $4 B, C$ ). CNO increased the percentage of time spent on the open arms of the EPM $\left(U=20,{ }^{* *} p=0.0065\right.$, Mann-Whitney test) and the percentage of open arm entries on the EPM $\left(t_{(20)}=\right.$ 5.647, ${ }^{* * * *} p<0.0001$, unpaired $t$ test) without affecting the number of closed arm entries $(U=57, p=0.8451$, Mann-Whitney test, $n=11$ both groups; Fig. $4 B$ ). Exploratory rearing and grooming are ethological behaviors sensitive to stress and anxiety levels (Kalueff et al., 2016; Sturman et al., 2018). We found that $\mathrm{CeA}^{\mathrm{CRF}}$ terminal inhibition increased rearing events $\left(t_{(20)}=\right.$ $4.375,{ }^{* *} p=0.003$, unpaired $t$ test; Fig. $4 B$ ) and decreased grooming events (Vehicle median 1.0, CNO median: $0.0 ; U=26$, ${ }^{\star} p=0.0216$, Mann-Whitney test, $n=11$ both groups) on the EPM. CNO also increased time spent $\left(U=21,{ }^{*} p=0.0081\right.$, Mann-Whitney test) and distance traveled in the center of the OF after IMS ( $U=24,{ }^{\star} p=0.0153$, Mann-Whitney test) without altering the total distance traveled $\left(t_{(20)}=0.4655, p=0.6466\right.$, unpaired $t$ test, $n=11$ both groups; Fig. $4 C$ ).

Next, to investigate whether $\mathrm{CRF}^{\mathrm{CeA}}$ inputs to the dlBST were sufficient to enhance anxiety, we expressed hM3Dq in CRF ${ }^{\mathrm{CeA}}$ neurons and directed guide cannulas to the dBBST to activate $\mathrm{CRF}^{\mathrm{CeA}}$ terminals there (Wang et al., 2015) (Fig. 4A). Microinfusion of CNO ( $1 \mathrm{~mm}$ in $0.3 \mu \mathrm{l} ; 300 \mathrm{pmol}$ ) into the dlBST reduced the percentage of time spent on the open arms of the EPM, which was prevented with local injection of R121919 ( $1 \mu \mathrm{g}$ in $0.3 \mu \mathrm{l})$
$\left(F_{\mathrm{hM} 3 \mathrm{Dq}} \times \mathrm{R} 12(1,31)=9.83,{ }^{* *} p=0.0037\right.$, two-way ANOVA, $n=$ $8-12 ;{ }^{* * *} p=0.0012 \mathrm{mCh}:$ Veh compared with hM3:Veh; ${ }^{* * * *} p<0.0001$ hM3:Veh compared with hM3:R12 by Tukey's test; Fig. 4D). Likewise, microinfused CNO reduced the percentage of open arm entries on the EPM, which was also prevented by administration of R121919 in the dlBST $\left(F_{\mathrm{hM} 3 \mathrm{Dq}} \times \mathrm{R} 12(1,31)=\right.$ 33.84, ${ }^{* * * *} p<0.0001$, two-way ANOVA, $n=8-12$; ${ }^{* * *} p<$ 0.0001 for mCh:Veh compared with hM3:Veh, and for hM3:Veh compared with hM3:R12 by Tukey's test; Fig. 4D). CeA ${ }^{\text {CRF }}$ terminal excitation reduced rearing, which was prevented by $\mathrm{R} 121919\left(F_{\mathrm{hM} 3 \mathrm{Dq}} \times \mathrm{R} 12(1,31)=11.46,{ }^{* *} p=0.0019\right.$, two-way ANOVA, $n=8-12 ;{ }^{* * *} p=0.0002$ for $\mathrm{mCh}: V e h$ compared with hM3:Veh, and ${ }^{* *} p=0.0013$ for hM3:Veh compared with hM3:R12 by Tukey's test; Fig. $4 D)$. Grooming was not affected $\left(F_{\mathrm{hM} 3 \mathrm{Dq}} \times \mathrm{R} 12(1,31)=0.022, p=0.8839, F_{\mathrm{hM} 3 \mathrm{Dq}}=0.927, F_{\mathrm{R} 12}=\right.$ $0.237, n=8-12)$. Similar results were observed in the OF test. $\mathrm{CNO}$ reduced time spent in the center of the OF, which was prevented by local blockade of CRF1 receptors $\left(F_{\mathrm{hM} 3 \mathrm{Dq}} \times \mathrm{R} 12\right.$ $(1,32)=6.224,{ }^{\star} p=0.0180, n=8-12 ;{ }^{* * * *} p=0.0001$ for mCh:Veh compared with hM3:Veh and ${ }^{\star * *} p=0.0009$ for hM3: Veh compared with hM3:R12 by Tukey's test; Fig. 4E). CNO also reduced the percentage of total distance traveled that was in the center of the OF, and this was also prevented by R121919 $\left(F_{\mathrm{hM} 3 \mathrm{Dq} \times \mathrm{R} 12}(1,32)=6.56,{ }^{\star} p=0.0153, n=8-12{ }^{* * \star} p=0.002\right.$ for mCh:Veh compared with hM3:Veh, and ${ }^{\star * *} p=0.003$ for hM3:Veh compared with hM3:R12 by Tukey's test; Fig. $4 E$ ). $\mathrm{CNO}$ modestly reduced the total distance traveled in the OF in animals that expressed hM3Dq in $\mathrm{CRF}^{\mathrm{CeA}}$ neurons, but R121919 in the dlBST had no effect on this measure $\left(F_{\mathrm{hM} 3 \mathrm{Dq}}(1,32)=\right.$ 14.77, ${ }^{* *} p=0.0005 ; F_{\mathrm{R} 12}(1,32)=1.645, p=0.209$; $F_{\mathrm{hM} 3 \mathrm{Dq}} \times \mathrm{R} 12(1,33)=0.65, p=0.426, n=8-12$; Fig. $\left.4 E\right)$. Finally, CNO infusion into the dlBST reduced social interaction time, which was also reversed by R121919 infusion $\left(F_{\mathrm{hM} 3 \mathrm{Dq}} \times \mathrm{R} 12\right.$ $(1,33)=24.22,{ }^{\star * \star *} p<0.0001, n=8-12 ;{ }^{\star * * *} p<0.0001$ for mCh:Veh compared with hM3:Veh and for hM3:Veh compared with hM3:R12 by Tukey's tests; Fig. $4 F$ ). To ensure that the dose 

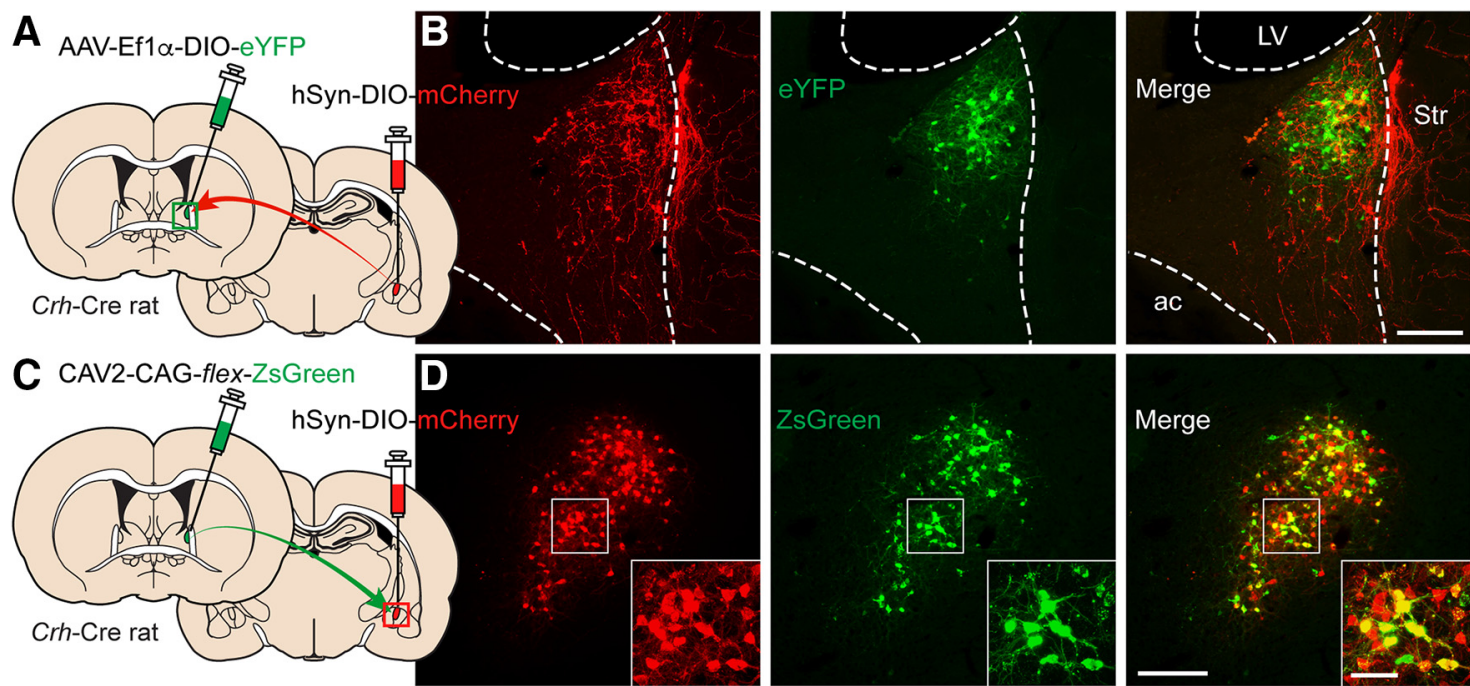

E

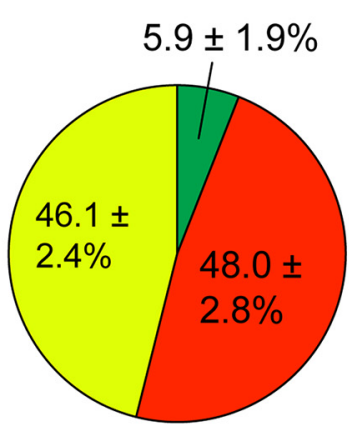

ZsGreen only

$\mathrm{mCh}$ only

ZsGreen $+\mathrm{mCh}$
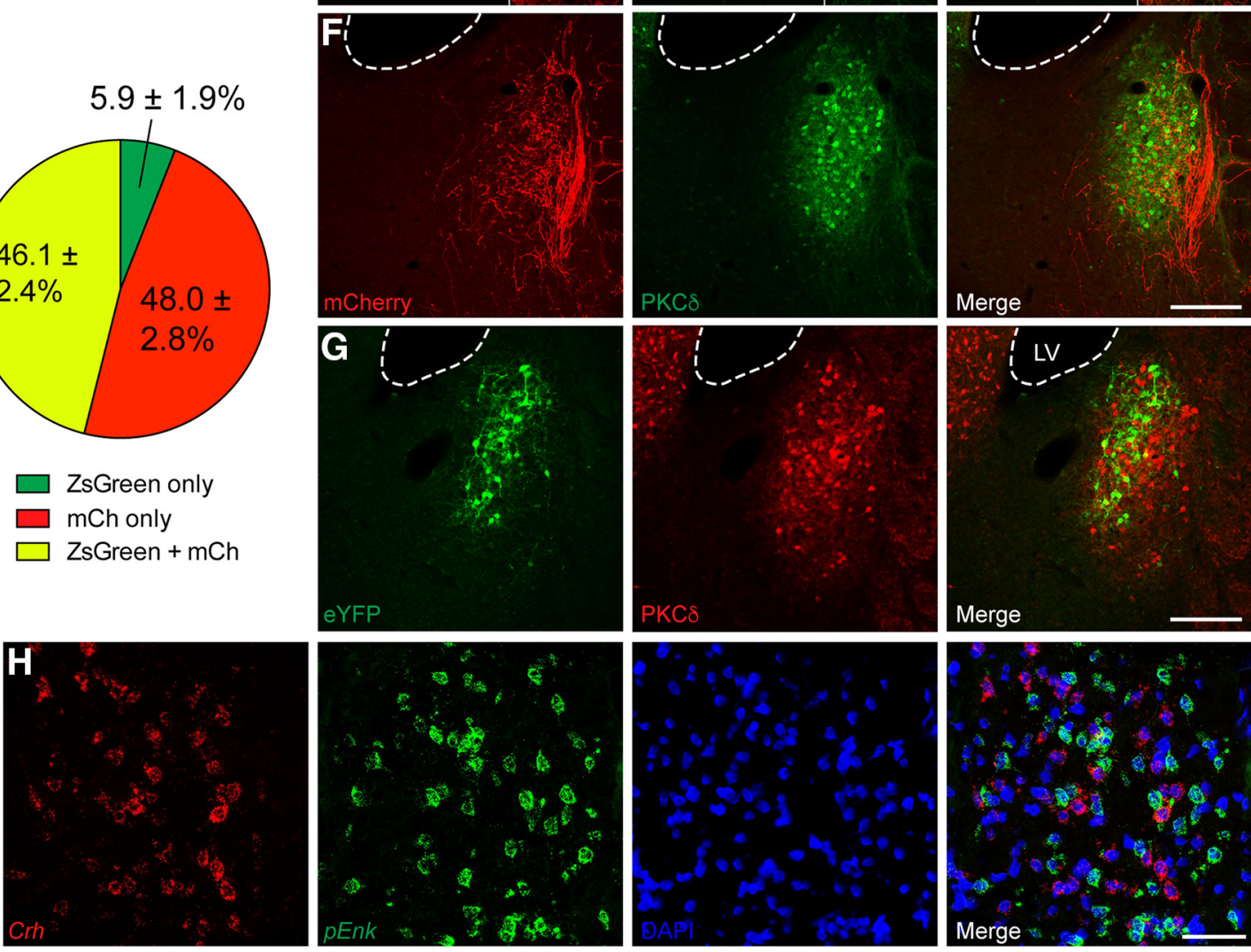

Figure 3. $\quad \mathrm{CRF}^{\mathrm{CeA}}$ neurons target the dIBST. A, Configuration of dual viral injections into the dIBST and CeA of Crh-Cre rats for anterograde tracing. $\boldsymbol{B}, \mathrm{A}_{\text {dense plexus of } \mathrm{mCherry}}{ }^{+} \mathrm{CRF}{ }^{\mathrm{CeA}}$ fibers was detected in the dIBST in the vicinity of eYFP ${ }^{+}$CRF $^{\text {dlBST }}$ neurons. Scale bar, $200 \mu \mathrm{m}$. LV, Lateral ventricle; Str, striatum; ac, anterior commissure. C, Configuration of dual viral injections into the dIBST and CeA of Crh-Cre rats for retrograde tracing. D, Many mCherry ${ }^{+}$CRF neurons in the CeA were retrogradedly labeled with CAV2-packaged ZsGreen. Scale bar, $200 \mu \mathrm{m}$. Boxed region is enlarged in inset. Scale bar, $50 \mu \mathrm{m}$. E, Quantification of ZsGreen expressed in CeA cell bodies revealed that $\sim 46.1 \%$ (total of 1465 neurons counted from 3 to 6 BST sections from 5 rats) of CRF ${ }^{\text {CeA }}$ $\left(\mathrm{mCh}^{+}\right)$neurons project to the dIBST. $\boldsymbol{F}, \mathrm{CRF}^{\mathrm{CeA}}$ inputs cluster around PKC $\delta$ neurons in the oval nucleus. Scale bar, $200 \mu \mathrm{m} . \boldsymbol{G}$ and $\boldsymbol{H}, \mathrm{CRF}^{\mathrm{dBSST}}$ neurons are distinct from PKC $\delta$ neurons $(\boldsymbol{G})$ and from cells expressing proenkephalin $(\boldsymbol{H})$. Scale bars: $\mathbf{G}, 200 \mu \mathrm{m} ; \boldsymbol{H}, 50 \mu \mathrm{m}$. mCh (mCherry), LV (lateral ventricle), pEnk (proenkephalin).

of $\mathrm{CNO}$ we used did not produce off-target effects, we implanted guide cannulas over the dlBST of nontransgenic Wistar rats and found no effect of 300 pmol CNO on IMS-induced anxiety (Fig. $5 A-C)$. Importantly, these findings indicate that $\mathrm{CRF}^{\mathrm{CeA}}$ inputs to the dlBST are necessary and sufficient for increasing anxietylike behavior, likely through release of CRF and activation of CRF1 receptors in the dIBST.

Because systemic administration of R121919 inhibited IMSinduced anxiety-like behavior, we investigated whether R121919 could also block anxiety-like behavior induced by activation of $\mathrm{CRF}^{\mathrm{CeA}}$ inputs to the dlBST. Systemic administration of R121919 $(20 \mathrm{mg} / \mathrm{kg}$, s.c.) prevented anxiety-like behavior induced by microinfusion of CNO into the dlBST in rats that expressed hM3Dq in $\mathrm{CRF}^{\mathrm{CeA}}$ neurons. CNO decreased the percentage of time in the open arms $\left(F_{\mathrm{CNO}} \times \mathrm{R} 12(1,37)=4.678,{ }^{*} p=0.0371\right.$, two-way ANOVA, $n=9-11 ;{ }^{*} p=0.0282$ for Vehicle:Veh compared with Vehicle:CNO, and ${ }^{*} p=0.0378$ for Vehicle:CNO compared with R12:CNO by Tukey's test; Fig. $5 E$ ) and the percentage of open 
A

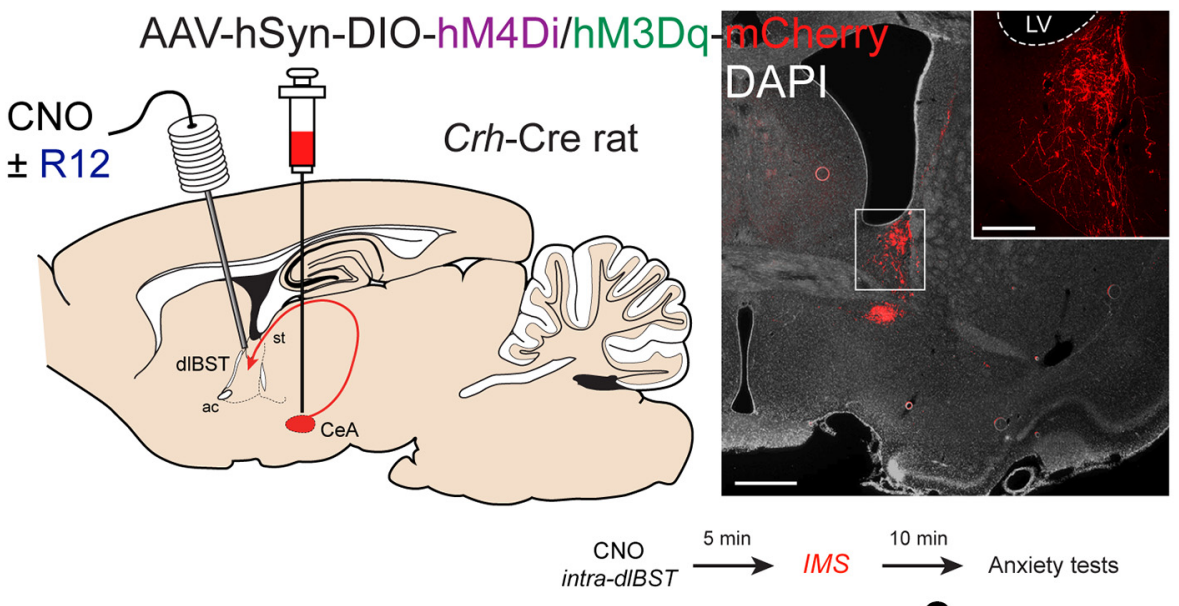

B
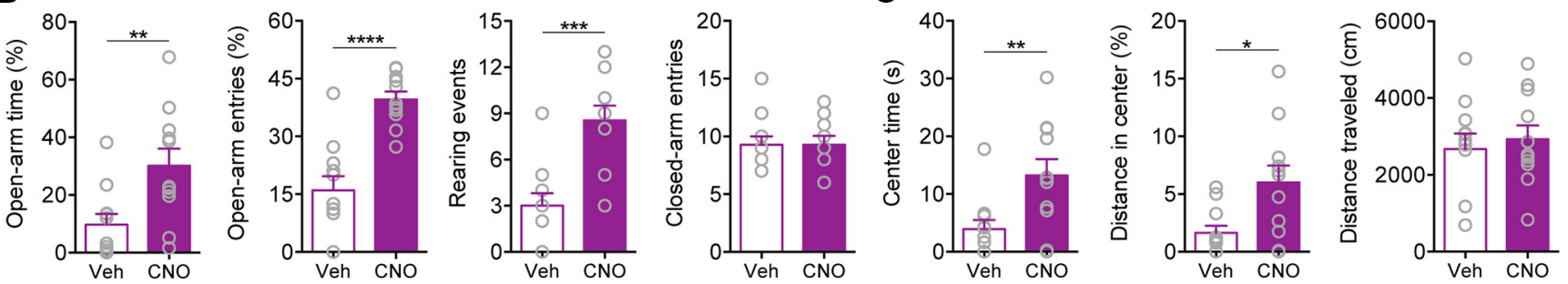

D

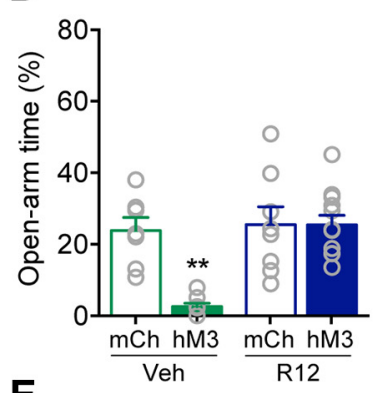

$\mathbf{E}$

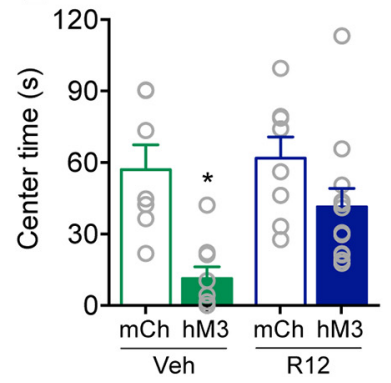

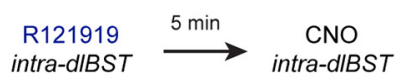

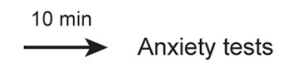

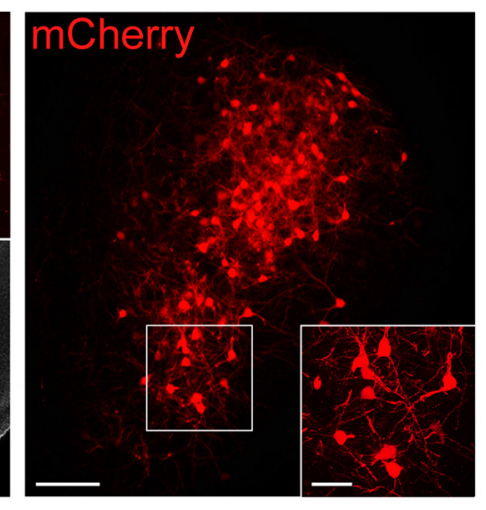
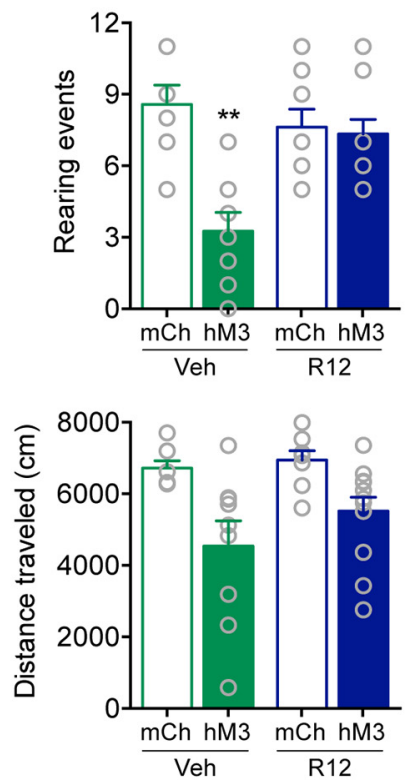

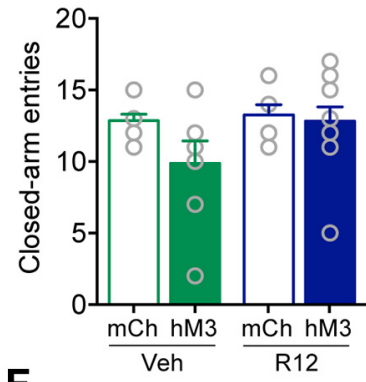

$\mathbf{F}$

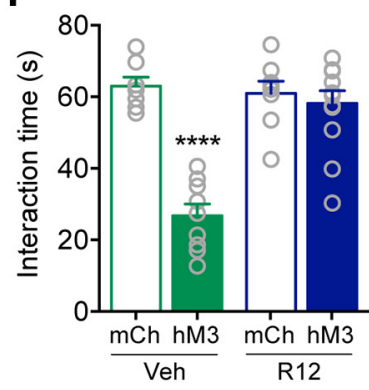

Figure 4. CRF ${ }^{\mathrm{CeA}}$ projections to dIBST mediate anxiety. A, AAV encoding Cre-dependent inhibitory hM4Di or excitatory hM3Dq was injected into the CeA with guide cannulas directed to the dIBST for targeted CNO microinjection. Left, CRF ${ }^{\mathrm{CeA}}$ fibers targeting the dIBST. Scale bar, $500 \mu \mathrm{m}$. Boxed region is enlarged in inset. Scale bar, $50 \mu \mathrm{m}$. Right, dIBST-projecting CRF ${ }^{\mathrm{CeA}}$ neurons. Scale bar, $200 \mu \mathrm{m}$. Boxed region is enlarged in inset. Scale bar, $20 \mu \mathrm{m}$. B, Inhibition of CRF ${ }^{\mathrm{CeA}}$ terminals in the dIBST with CNO (1 mm in $0.3 \mu$ ) increased the percentage of time spent on the open arms of the EPM, the percentage of open arm entries, and the number of rearing events without affecting the number of closed arm entries. C, Activation of hM4Di with CNO also increased time spent in the center of the $\mathrm{OF}$ and the distance traveled in the center without altering the total distance traveled after IMS. D. Activation of CRF CeA terminals in the dIBST with CNO (1 mM in $0.3 \mu l$ ) reduced the percentage of time spent on the open arms of the EPM, the percentage of open arm entries, and the number of rearing events, which was prevented with local injection of R121919 (1 $\mu \mathrm{g}$ in $0.3 \mu \mathrm{l}$ ). $E$, Activation of terminals also reduced time spent in the center and distance traveled in the center of the $0 F$, which was prevented by local blockade of CRF1 receptors. CN0 modestly reduced the total distance traveled in the OF in animals that expressed hM3Dq in CRF ${ }^{\mathrm{CeA}}$ neurons, whereas R121919 in the dIBST had no effect. $\boldsymbol{F}$, Terminal activation reduced social interaction time, which was CRF1 receptor-dependent. Data are mean \pm SEM. ${ }^{*} p<0.05,{ }^{* *} p<0.01,{ }^{* * *} p<0.001,{ }^{* * * *} p<0.0001$. Veh (vehicle), R12 (R121919), mCh (mCherry), hM3 (hM3Dq), LV (lateral ventricle).

arm entries on the $\operatorname{EPM}\left(F_{\mathrm{CNO}} \times \mathrm{R} 12(1,37)=25.69,{ }^{* * * *} p<\right.$ 0.0001 , two-way ANOVA, $n=9-11 ;{ }^{* * * *} p<0.0001$ compared with other conditions by Tukey's test; Fig. $5 E$ ), without altering the number of closed arm entries $\left(F_{\mathrm{CNO}} \times \mathrm{R} 12(1,37)=0.2072\right.$, $p=0.6517$, two-way ANOVA, $n=9-11$; Fig. 5E). Likewise, $\mathrm{CNO}$ microinfusion decreased the percentage of time spent in the OF, and this effect was prevented by systemic R121919 $\left(F_{\mathrm{CNO}} \times \mathrm{R} 12\right.$ $(1,37)=5.999,{ }^{\star} p=0.0192$, two-way ANOVA, $n=9-11 ;{ }^{* *} p=$ 


\section{A Clozapine-N-Oxide}

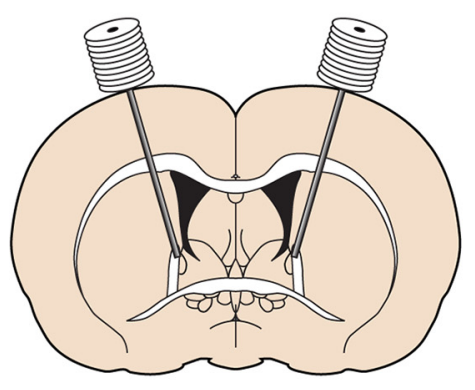

WT wistar rat
B
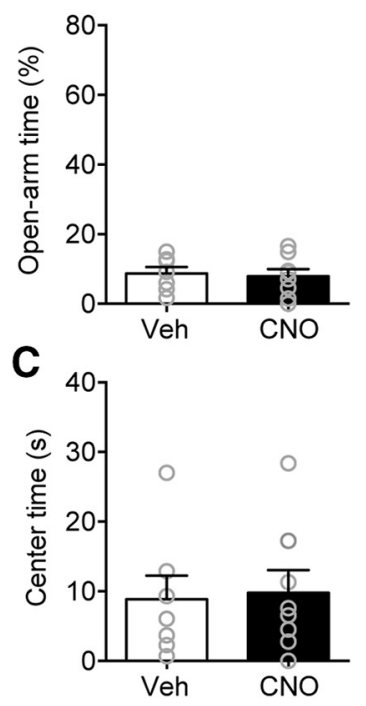
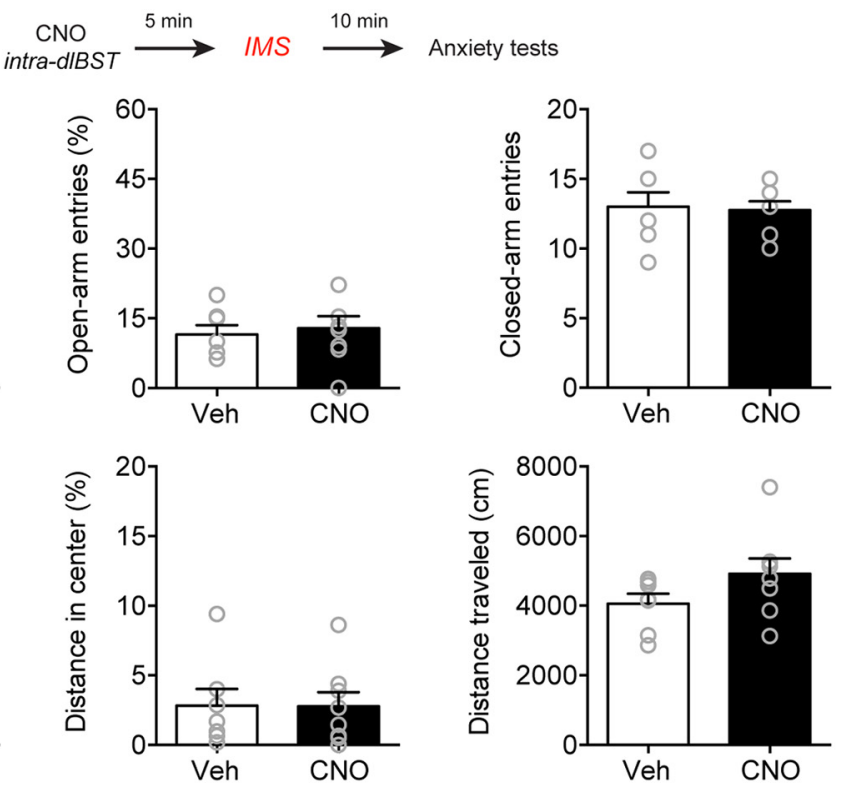

\section{AAV-hSyn-DIO-hM3Dq-mCherry}
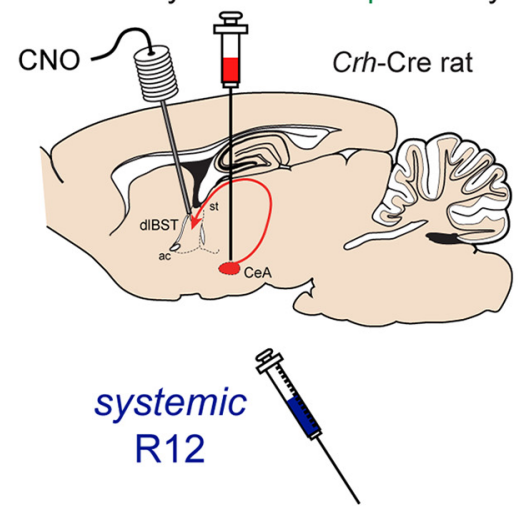

E

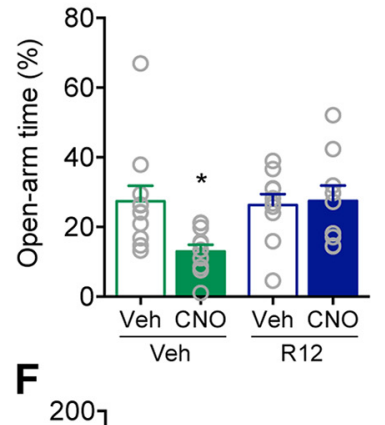

$\underset{\text { subcutaneous }}{\mathrm{R} 121919} \stackrel{30 \mathrm{~min}}{\longrightarrow} \underset{\text { intra-dlBST }}{\mathrm{CNO}} \stackrel{10 \mathrm{~min}}{\longrightarrow}$
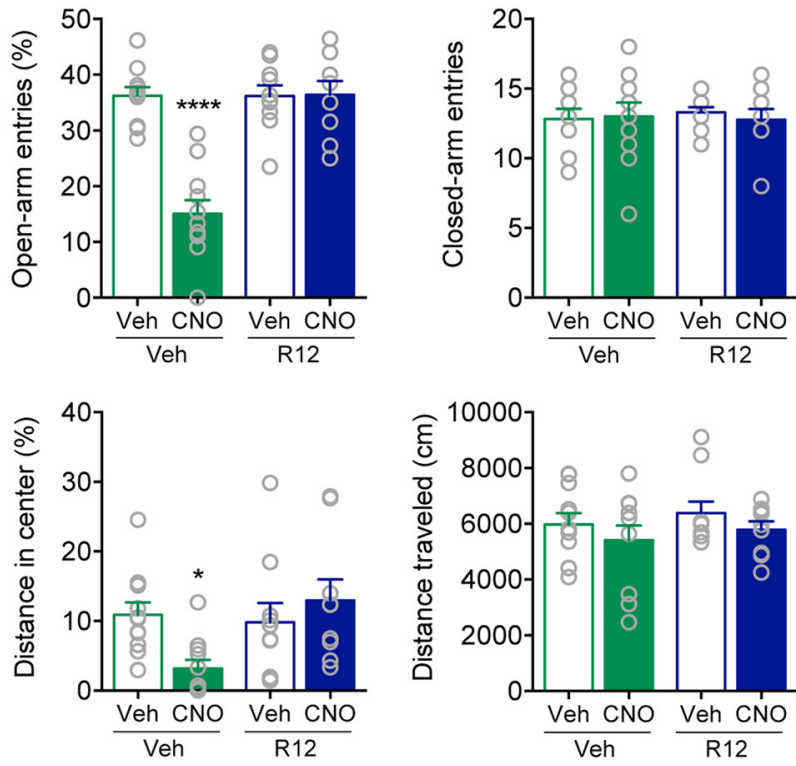

Figure 5. CNO has no effect in WT rats and systemic CRF1 receptor blockade prevents anxiety produced by CRF ${ }^{\mathrm{CeA}}$ terminal stimulation in the dIBST. $A$, WT Wistar rats were cannulated in the dIBST and microinjected with CNO (1 mM in $0.3 \mu$ l) before stress. B, Top, Experimental protocol. Bottom, CNO administration in the dIBST in the absence of DREADD expression in CRF ${ }^{\text {CeA }}$ terminals did not alter the time spent in the open arms $\left(t_{(13)}=0.2981, p=0.7703, n=7\right.$ Veh, 8 CNO, unpaired $t$ test), entries into the open arms $\left(t_{(13)}=0.4071, p=0.6906, n=7\right.$ Veh, 8 CNO, unpaired $t$ test $)$, or entries into the closed arms of the EPM ( $t_{(13)}=0.2089, p=0.8378, n=7$ Veh, 8 CNO, unpaired $t$ test). $C$, CN0 also did not change time spent in the center $\left(t_{(13)}=0.2022, p=0.8429, n=7\right.$ Veh, $8 \mathrm{CNO}$, unpaired $t$ test), distance traveled in the center $\left(U=26, p=0.8665, n=7\right.$ Veh, $8 \mathrm{CNO}$, Mann-Whitney test), or total distance traveled in the $0 \mathrm{~F}\left(t_{(13)}=1.573, p=0.1397, n=7 \mathrm{Veh}\right.$, $8 \mathrm{CNO}$, unpaired $t$ test). D, Crh-Cre rats were injected with hM3Dq into the CeA and cannulated in the dIBST. Rats were microinjected with CNO ( $1 \mathrm{~mm}$ in $0.3 \mu \mathrm{l})$ to activate terminals after a systemic injection of R121919. E, Top, Experimental protocol. Bottom, Systemic administration of R121919 prevented hM3Dq-induced decreases in the percentage of time in the open arms and the percentage of open arm entries, without altering the number of closed arm entries. $\boldsymbol{F}$, Systemic administration of R121919 also prevented hM3Dq-induced decreases in the percentage of time spent in the $0 \mathrm{~F}$ and the distance traveled in the center without affecting total distance traveled in the OF. Data are mean \pm SEM. ${ }^{*} p<0.05,{ }^{* * * *} p<0.0001$. WT (wild type), Veh (vehicle), R12 (R121919).

0.0086 for Vehicle:CNO compared with R12:CNO by Tukey's test; Fig. $5 F)$. CNO also reduced the distance traveled in the center of the OF, and this effect was prevented by systemic R121919 $\left(F_{\mathrm{CNO}} \times \mathrm{R} 12(1,37)=5.886,{ }^{*} p=0.0203\right.$, two-way ANOVA, $n=$ $9-11 ;{ }^{*} p=0.0212$ for Vehicle:CNO compared with R12:CNO by Tukey's test; Fig. $5 F$ ). Because both systemic and local administration of R121919 into the dlBST reversed anxiety-likely behavior induced by activation of $\mathrm{CRF}^{\mathrm{CeA}}$ inputs to the dlBST, it is likely that that systemic R121919 inhibits anxiety-like behavior through actions at CRF1 receptors in the dlBST.

\section{Extended amygdala CRF network for anxiety}

Because activation of $\mathrm{CRF}^{\mathrm{CeA}}$ inputs to the dlBST can drive anxiety-like behavior and the dlBST also contains neurons that produce CRF, we investigated whether $\mathrm{CRF}^{\mathrm{CeA}}$ and $\mathrm{CRF}^{\mathrm{dlBST}}$ neurons act within a common network to drive anxiety. We in- 
A AAV-hSyn-DIO-KORD-IRES-mCitrine B
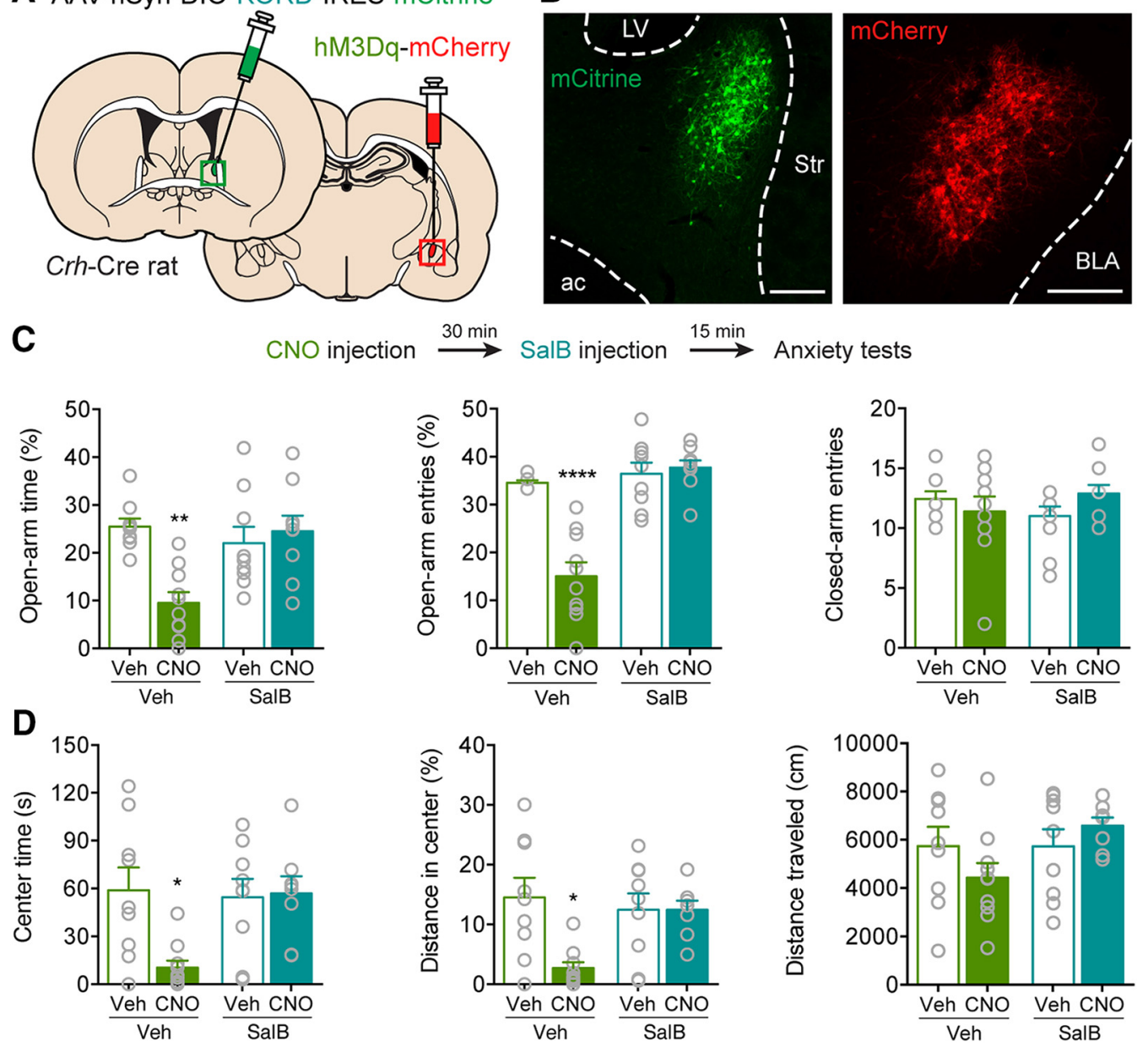

Figure 6. Extended amygdala CRF network for eliciting anxiety. A, AAV encoding Cre-dependent KORD was injected into the dIBST, and AAV encoding Cre-dependent hM3Dq was injected into the ipsilateral CeA. B, Example of antibody-amplified mCitrine fluorescence in CRF ${ }^{\mathrm{dBST}}$ neurons and native mCherry in CRF ${ }^{\mathrm{CeA}}$ neurons. Scale bars, $200 \mu \mathrm{m}$. C, Top, Experimental protocol. Bottom, Inhibition of CRF ${ }^{\text {dBST }}$ neurons with SaIB prevented CNO-induced decreases in the percentage of time in the open arms of the EPM and reductions of open arm entries on the EPM without affecting closed arm entries. SalB also prevented CNO-induced decreases in time spent in the center of the OF. D, In the OF, CNO reduced the time spent in the center and distance traveled in the center, but coadministration of SalB prevented this effect without affecting the total distance traveled. Data are mean \pm SEM. ${ }^{*} p<0.05,{ }^{* *} p<0.01,{ }^{* * * *} p<0.0001$. Veh (vehicle), LV (lateral ventricle), Str (striatum), ac (anterior commissure), BLA (basolateral amygdala).

jected the CeA of Crh-Cre rats with an AAV to express the excitatory designer receptor $\mathrm{hM} 3 \mathrm{Dq}$ on one side of the brain and injected the ipsilateral dlBST with an AAV to express Credependent KORD-IRES-mCitrine ( $\kappa$ opioid receptor DREADD), a complementary inhibitory designer receptor (Fig. 6A,B). Unstressed rats were administered $\mathrm{CNO}$ followed by the KORDspecific ligand SalB (15 mg/kg, s.c.), and then were tested for anxiety-like behavior. Rats given $\mathrm{CNO}$ to excite $\mathrm{CRF}^{\mathrm{CeA}}$ neurons displayed significant anxiety-like behavior on the EPM and in the OF. Importantly, coadministration of SalB to inhibit CRF ${ }^{\text {dlBST }}$ neurons blocked the anxiety-like behaviors evoked by activating $\mathrm{CRF}^{\mathrm{CeA}}$ neurons (Fig. 6C,D). As expected, systemic administration of CNO (2 mg/kg, i.p.) decreased in the percentage of open arm time in the EPM, and this effect was prevented by inhibiting $\mathrm{CRF}^{\text {dlBST }}$ neurons with SalB $\left(F_{\mathrm{CNO}} \times\right.$ SalB $(1,34)=10.33,{ }^{* *} p=$ 0.0029 , two-way ANOVA, $n=9$ or $10 ;{ }^{* *} p=0.0011$ for Vehicle: Veh compared with Vehicle:CNO and ${ }^{* *} p=0.0023$ for Vehicle: CNO compared with SalB:CNO by Tukey's tests; Fig. 6C). CNO also reduced the percentage of open arm entries on the EPM, and coadministration of SalB also prevented this effect $\left(F_{\mathrm{CNO}} \times\right.$ SalB $(1,33)=24.54,{ }^{* * *} p<0.0001, n=9$ or $10 ;{ }^{* * * *} p<0.0001$ compared with other conditions by Tukey's test; Fig. 6C). No effect on the number of closed arm entries was detected $\left(F_{\mathrm{CNO}} \times\right.$ SalB $(1,33)=2.610, p=0.1155, n=9$ or 10 ; Fig. $\left.6 C\right)$. SalB also prevented CNO-induced decreases in time spent in the center of the $\mathrm{OF}\left(F_{\mathrm{CNO}} \times\right.$ SalB $(1,32)=5.751,{ }^{\star} p=0.0225, n=8-10$; ${ }^{\star} p=0.0113$ for Vehicle:Veh compared with Vehicle:CNO and ${ }^{\star} p=0.0203$ for Vehicle:CNO compared with SalB:CNO by Tukey's test; Fig. 6D), and in the distance traveled in the center $\left(F_{\mathrm{CNO}} \times\right.$ SalB $(1,32)=6.475,{ }^{*} p=0.0160, n=8-10 ;{ }^{* *} p=0.0042$ for Vehicle:Veh compared with Vehicle:CNO, and ${ }^{\star} p=0.0275$ for Vehicle:CNO compared with SalB:CNO by Tukey's test; Fig. $6 D$ ), without affecting the total distance traveled in the $\mathrm{OF}$ $\left(F_{\mathrm{CNO}} \times\right.$ SalB $(1,32)=2.718, p=0.1090 ; n=8-10 ;$ Fig. $\left.6 D\right)$. These results are consistent with the hypothesis that $\mathrm{CRF}^{\mathrm{CeA}}$ neurons engage CRF ${ }^{\text {dlBST }}$ neurons to drive anxiety-like behavior. They also demonstrate that unilateral activation of $\mathrm{CRF}^{\mathrm{CeA}}$ neurons is sufficient to increase anxiety-like behavior.

Because CRF ${ }^{\text {dlBST }}$ neurons were necessary for the anxiety-like behaviors produced by activating $\mathrm{CRF}^{\mathrm{CeA}}$ neurons, we next examined whether this CRF-to-CRF cell network interaction was important for anxiety induced by stress. We disconnected this postulated CRF network by expressing Cre-dependent caspase3, which lesions neurons, in the CeA of one side of the brain and in 
A

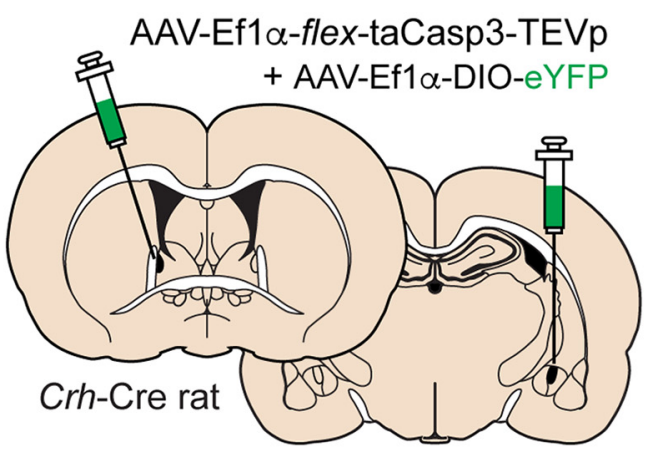

B

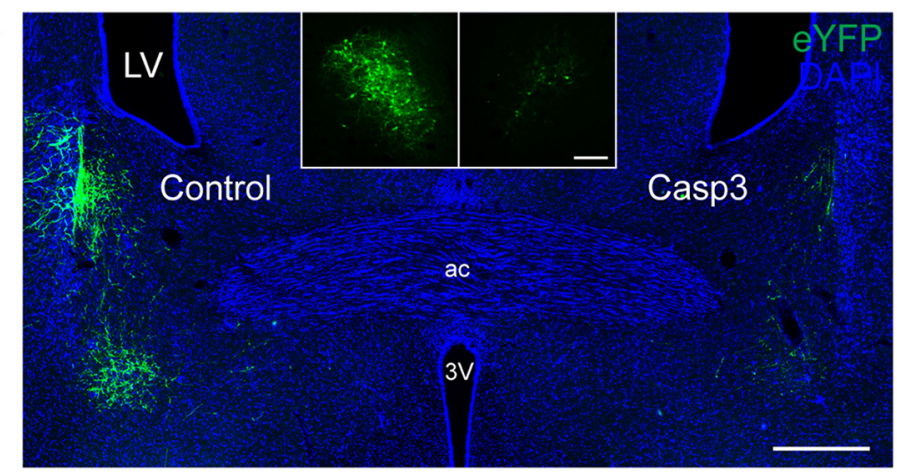

\section{Casp3 injection $\stackrel{4-6 \text { wks }}{\longrightarrow}$ IMS $\stackrel{10 \mathrm{~min}}{\longrightarrow}$ Anxiety tests}

C
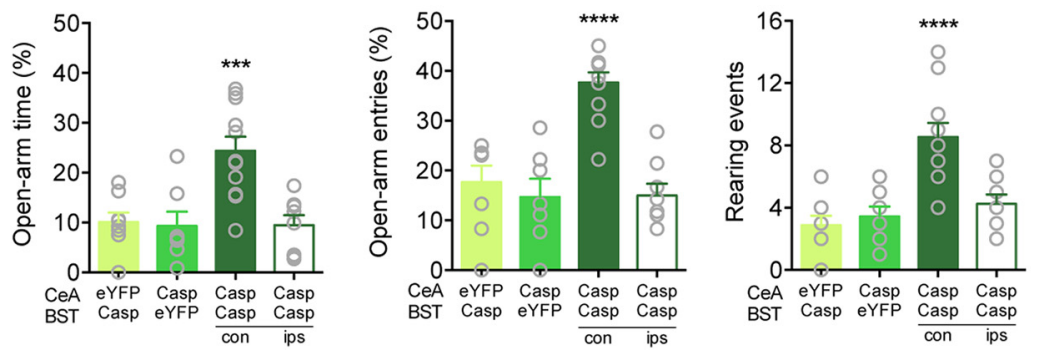

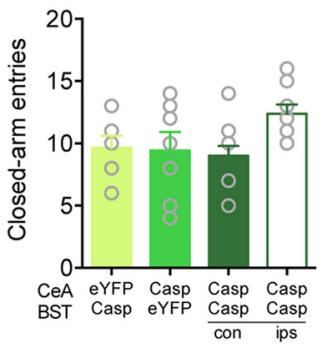

D

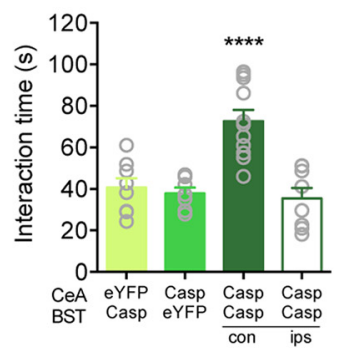

Figure 7. Caspase3-mediated CRF circuit disconnection disrupts stress-induced anxiety. A, AAV carrying flex-taCaspase3 was injected into the dIBST and the contralateral CeA for disconnection of the extended amygdala CRF network. B, Caspase3 ablates CRF ${ }^{\mathrm{CeA}}$ neurons and their fibers in the BST. Example image of CRF ${ }^{\mathrm{CeA}}$ terminal eYFP expression in the dIBST of animal injected with eYFP + PBS (Control) in the left CeA and eYFP + Caspase3 in the right CeA. Scale bar, $500 \mu \mathrm{m}$. Inset, eYFP expression in the respective CeA for each side. Scale bar, $200 \mu \mathrm{m}$. C, Expression of caspase 3 in contralateral $\mathrm{CRF}^{\mathrm{CeA}}$ and $\mathrm{CRF}^{\mathrm{d} \text { IBST }}$ neurons increased the percentage of time spent on the open arms of the EPM, the percentage of open arm entries, and the number of rearing events without significantly affecting locomotion. $D$, Caspase3-mediated CRF circuit disconnection before IMS also increased social interaction time. Data are mean \pm SEM. ${ }^{* *} p<0.001,{ }^{* * *} p<0.0001$. Casp3 or Casp (caspase3), con (contralateral), ips (ipsilateral), LV (lateral ventricle).

the contralateral dlBST (Fig. 7A). This disconnection procedure prevented IMS-induced anxiety in the EPM and social interaction tests, while unilateral ablation in either the CeA or dlBST alone, or ablation of CRF neurons in the CeA and dlBST of the same side, had no effect on stress-induced anxiety (Fig. 7C,D). Expression of caspase 3 in contralateral $\mathrm{CRF}^{\mathrm{CeA}}$ and $\mathrm{CRF}^{\mathrm{dBST}}$ neurons increased the percentage of time spent on the open arms of the $\operatorname{EPM}\left(F_{(3,30)}=9.675,{ }^{* *} p=0.0001, n=7-11 ;{ }^{* *} p=\right.$ 0.0015 for contralateral ablation compared with either eYFP group, and ${ }^{* * *} p=0.0009$ for contralateral ablation compared with ipsilateral ablation by Tukey's test; Fig. 7C). Expression of caspase 3 in contralateral $\mathrm{CRF}^{\mathrm{CeA}}$ and $\mathrm{CRF}^{\mathrm{dlBST}}$ neurons also increased the percentage of open arm entries on the $\operatorname{EPM}\left(F_{(3,30)}=\right.$ $18.49{ }^{* * * *} p<0.0001, n=7-11{ }^{* * * *} p<0.0001$ for contralateral ablation compared with other conditions by Tukey's test; Fig. $7 C)$ and rearing events $\left(F_{(3,30)}=13.31,{ }^{* * *} p<0.0001, n=7-11\right.$; ${ }_{* * * *} p<0.0001$ for contralateral ablation compared with either eYFP group, and ${ }^{* *} p=0.0013$ compared with ipsilateral ablation by Tukey's test; Fig. $7 C$ ) without significantly affecting the number of closed arm entries $\left(F_{(3,30)}=2.424, p=0.0852, n=7-11\right.$; Fig. $7 C)$. Grooming behavior was not significantly affected $\left(F_{(3,30)}=1.614, p=0.2068, n=7-11\right)$. Finally, expression of caspase3 in contralateral CRF ${ }^{\mathrm{CeA}}$ and $\mathrm{CRF}^{\mathrm{dIBST}}$ neurons reduced time spent in social interaction $\left(F_{(3,30)}=15.07,{ }^{* * * *} p<0.0001\right.$, $n=7-11$ rats; ${ }^{* * *} p=0.0002$ for contralateral ablation compared with either eYFP group, and ${ }^{* * * *} p<0.0001$ for contralateral ablation compared with ipsilateral ablation by Tukey's test; Fig. $7 D)$. Together, these results indicate that $\mathrm{CRF}^{\mathrm{CeA}}$ and $\mathrm{CRF}^{\mathrm{dIBST}}$ neurons function within a common network to mediate stressinduced anxiety-like behavior in rats.

\section{Discussion}

Here we demonstrate the existence of a $\mathrm{CRF}^{\mathrm{CeA}}$ to $\mathrm{CRF}^{\mathrm{dlBST}}$ neuronal network that drives stress-induced anxiety-like behavior in rats. This network involves $\mathrm{CRF}^{\mathrm{CeA}}$ inputs to the dlBST and activation of CRF1 receptors and CRF neurons in the dlBST. Importantly, our findings indicate that CRF neurons in the CeA and BST cooperate to generate a state of anxiety following stress, which concurs with recent evidence of CeA and BST coupling in humans and nonhuman primates exhibiting anxiety (Gungor and Paré, 2016; Shackman and Fox, 2016).

Two previous studies have suggested a role for $\mathrm{CRF}^{\mathrm{CeA}}$ neurons in driving anxiety-like behaviors in mice. In one, CRF knockdown in the CeA reduced stress-induced anxiety (Regev et al., 2012), and in the other, optogenetic stimulation of $\mathrm{CRF}^{\mathrm{CeA}}$ terminals in the brainstem evoked anxiety-like behavior (McCall et al., 2015). Our study adds important new findings to the evolving literature on anxiety circuitry by demonstrating in rats that $\mathrm{CRF}^{\mathrm{CeA}}$ projections to the BST and functional coupling of CeA and dlBST CRF neurons are necessary and sufficient for expression of stress-induced anxiety. One caveat is that optogenetic or chemogenetic activation may provide stronger drive than occurs endogenously, and the sufficiency of activating a given cell type to cause anxiety does not imply that other circuit elements are not also important with respect to endogenous activity of the CRF system. In this regard, because stimulation of $\mathrm{CRF}^{\mathrm{CeA}}$ projections to the locus coeruleus (McCall et al., 2015) or the dlBST (the current study) can generate anxietylike behavior, one interesting and important question is whether these two pathways originate from the same or differ- 
ent $\mathrm{CRF}^{\mathrm{CeA}}$ neurons. Thus, future studies are needed to determine whether subpopulations of CRF neurons have different projection targets, and how different $\mathrm{CRF}^{\mathrm{CeA}}$ outputs could interact to drive anxiety-like behaviors.

Another important question is how CRF released from $\mathrm{CRF}^{\mathrm{CeA}}$ neurons affects dlBST circuitry to increase anxiety. We detected $\mathrm{CRF}^{\mathrm{CeA}}$ fibers throughout the dlBST, but most were clustered in the oval nucleus (Fig. $3 B$ ), which contains GABA neurons that promote anxiety, possibly through negative regulation of an anxiolytic anterodorsal subregion identified in mice (Kim et al., 2013). In rats, CRF ${ }^{\text {dlBST }}$ neurons cluster in the oval nucleus (Pomrenze et al., 2015), and are therefore more likely to be components of this circuitry than in mice where CRF neurons are scattered in the dlBST (Nguyen et al., 2016). It is also likely that $\mathrm{CRF}^{\mathrm{CeA}}$ neurons engage $\mathrm{CRF}^{\mathrm{dlBST}}$ neurons that project to remote regions, such as the hypothalamus or ventral tegmental area, to modulate anxiety (Marcinkiewcz et al., 2016; Dedic et al., 2018).

We found that anxiety-like behaviors driven by $\mathrm{CRF}^{\mathrm{CeA}}$ neuron activation (via hM3Dq) were dependent on $\mathrm{CRF}^{\text {dlBST }}$ neurons being active in the same hemisphere, supporting a cooperative role of the CeA and the BST in stress-induced anxiety. How $\mathrm{CRF}^{\mathrm{CeA}}$ neurons engage $\mathrm{CRF}^{\mathrm{dlBST}}$ neurons is not known. A simple explanation could be that CRF ${ }^{\text {dlBST }}$ neurons express CRF1 receptors and are excited directly by CRF. However, only presynaptic effects of CRF in the dlBST have been reported. In mice, CRF acting at CRF1 receptors can enhance glutamatergic neurotransmission in the dlBST (Kash et al., 2008; Nobis et al., 2011; Silberman et al., 2013). Thus, CRF release from CeA terminals in the dlBST might stimulate CRF ${ }^{\text {dlBST }}$ neurons by enhancing excitatory inputs onto those neurons. In addition, $\mathrm{CRF}^{\mathrm{CeA}}$ neurons project their axons to other structures that also project to the dlBST, such as the parabrachial nucleus and locus coeruleus (McCall et al., 2015; Pomrenze et al., 2015). Thus, because our CNO injections were systemic, it is possible that ipsilateral network effects indirectly recruited $\mathrm{CRF}^{\text {dlBST }}$ neurons. For example, recent findings (Nobis et al., 2011; McCall et al., 2015) support a positive feedforward circuit model (Koob, 1999) involving noradrenergic and CRF interactions in the locus coeruleus, CeA, and BST that drive stress-related anxiety. Thus, regardless of the mechanism, the serial interaction of $\mathrm{CRF}^{\mathrm{CeA}}$ and CRF dIBST neurons that we have identified likely promotes anxiety-like behavior through actions within a larger circuit.

Additional evidence indicates that local circuits within the lateral CeA can contribute to anxiety-like behavior. We previously found that rat $\mathrm{CRF}^{\mathrm{CeA}}$ neurons form inhibitory synapses with nearly half of non-CRF neurons in the lateral CeA (Pomrenze et al., 2015). A major subpopulation of non-CRF neurons expresses $\mathrm{PKC} \delta$; and in mice, optogenetic stimulation of CeA $\mathrm{PKC} \delta$ neurons promotes anxiety-like behavior (Botta et al., 2015). Because many mouse PKC $\delta$ neurons express CRF1 receptors (Sanford et al., 2017), local release of CRF might activate $\mathrm{CRF} 1$ receptors on rat $\mathrm{PKC} \delta$ neurons to promote anxiety. Another subpopulation of non-CRF neurons in the lateral CeA expresses the neuropeptide somatostatin. Compared with $\mathrm{PKC} \delta$ neurons, somatostatin neurons show greater connectivity with $\mathrm{CRF}^{\mathrm{CeA}}$ neurons (Fadok et al., 2017) and a larger proportion express CRF1 receptors in mice (Sanford et al., 2017). These characteristics agree with recent findings that CeA somatostatin neurons promote anxiety-like behavior through a circuit mechanism that recruits dlBST somatostatin neurons (Ahrens et al., 2018). Additionally, a recent study reported that chemogenetic activation of $\mathrm{CRF}^{\mathrm{CeA}}$ neurons in mice decreased locomotor activity and increased freezing on the EPM, which are behaviors proposed to model passive coping to environmental threats (Pliota et al., 2018). In that report, bath application of CRF increased the frequency of spontaneous EPSCs in CeA somatostatin neurons when tested in brain slices. These findings suggest that active CRF neurons can modulate local circuits in the CeA to orchestrate anxiety and other defensive behaviors in addition to the critical role that their dlBST projections play in stress-induced anxiety, as demonstrated here. It will be interesting in future studies to uncover how local and distant $\mathrm{CRF}^{\mathrm{CeA}}$ projections interact to generate anxiety-like behaviors.

In addition to $\mathrm{CRF}$ and GABA, $\mathrm{CRF}^{\mathrm{CeA}}$ neurons can release other neuropeptides (Pomrenze et al., 2015; Kim et al., 2017). Neurotensin in the rat oval BST can promote chronic stressinduced anxiety and cooperates with CRF to modulate synaptic transmission (Normandeau et al., 2018). In mice, the anxiogenic actions of dynorphin involve activation of $\kappa$ opioid receptors and inhibition of glutamate release from basolateral amygdala terminals in the anterodorsal BST (Crowley et al., 2016). Because several CRF ${ }^{\mathrm{CeA}}$ neurons express dynorphin (Pomrenze et al., 2015), they could be a source of dynorphin involved in these effects. Indeed, a recent paper reports that mice deficient in the tyrosine kinase receptor Erbb4 exhibit increased anxiety-like behavior because of increased activity of CeA neurons that express somatostatin and project to the dlBST, where they disinhibit dlBST somatostatin neurons through release of dynorphin into the dlBST (Ahrens et al., 2018). The contribution of dynorphin and other neuropeptides released from $\mathrm{CRF}^{\mathrm{CeA}}$ neurons, and their coordinated effects with neuropeptides released from other CeA subpopulations on synaptic physiology, remain to be determined.

A recent study demonstrated a role for $\mathrm{CRF}^{\mathrm{CeA}}$ projections to the dlBST in fear conditioning in the rat, where optogenetic silencing of these neurons during acquisition of conditioned fear suppressed freezing at later time points during retention testing, either due to impaired consolidation of long-lasting components of fear memory or acceleration of fear extinction (Asok et al., 2018). Together with our current work, these findings indicate that $\mathrm{CRF}^{\mathrm{CeA}}$ projections to the dlBST contribute to the generation of both stress-induced anxiety-like behavior and to the late, sustained phase of conditioned fear.

The availability of modern imaging and genetic tools has allowed discoveries that challenge previous notions about the dissociable roles of CeA and BST neurons in mediating fear and anxiety. Our results strongly support the hypothesis that both $\mathrm{CRF}^{\mathrm{CeA}}$ and $\mathrm{CRF}^{\mathrm{dlBST}}$ neurons are important for generating stress-induced anxiety-like behavior. In addition, our findings support the growing realization that the CeA and BST can interact as a tightly coupled functional unit (Shackman and Fox, 2016), and suggest that dysfunction of the $\mathrm{CRF}^{\mathrm{CeA} \rightarrow \mathrm{BST}}$ circuit could contribute to anxiety disorders in humans.

\section{References}

Ahrens S, Wu MV, Furlan A, Hwang GR, Paik R, Li H, Penzo MA, Tollkuhn J, Li B (2018) A central extended amygdala circuit that modulates anxiety. J Neurosci 38:5567-5583. CrossRef Medline

Asan E, Yilmazer-Hanke DM, Eliava M, Hantsch M, Lesch KP, Schmitt A (2005) The corticotropin-releasing factor (CRF)-system and monoaminergic afferents in the central amygdala: investigations in different mouse strains and comparison with the rat. Neuroscience 131:953-967. CrossRef Medline

Asok A, Draper A, Hoffman AF, Schulkin J, Lupica CR, Rosen JB (2018) Optogenetic silencing of a corticotropin-releasing factor pathway from the central amygdala to the bed nucleus of the stria terminalis disrupts sustained fear. Mol Psychiatry 23:914-922. CrossRef Medline 
Bale TL, Vale WW (2004) CRF and CRF receptors: role in stress responsivity and other behaviors. Annu Rev Pharmacol Toxicol 44:525-557. CrossRef Medline

Baxter AJ, Scott KM, Vos T, Whiteford HA (2013) Global prevalence of anxiety disorders: a systematic review and meta-regression. Psychol Med 43:897-910. CrossRef Medline

Binder EB, Nemeroff CB (2010) The CRF system, stress, depression and anxiety-insights from human genetic studies. Mol Psychiatry 15:574-588. CrossRef Medline

Botta P, Demmou L, Kasugai Y, Markovic M, Xu C, Fadok JP, Lu T, Poe MM, Xu L, Cook JM, Rudolph U, Sah P, Ferraguti F, Lüthi A (2015) Regulating anxiety with extrasynaptic inhibition. Nat Neurosci 18:1493-1500. CrossRef Medline

Buynitsky T, Mostofsky DI (2009) Restraint stress in biobehavioral research: recent developments. Neurosci Biobehav Rev 33:1089-1098. CrossRef Medline

Chen C, Wilcoxen KM, Huang CQ, Xie YF, McCarthy JR, Webb TR, Zhu YF, Saunders J, Liu XJ, Chen TK, Bozigian H, Grigoriadis DE (2004) Design of 2,5dimethyl-3-(6-dimethyl-4-methylpyridin-3-yl)-7-dipropylaminopyrazolo (1,5-a)py rimidine (NBI 30775/R121919) and structure-activity relationships of a series of potent and orally active corticotropin-releasing factor receptor antagonists. J Med Chem 47:4787-4798. CrossRef Medline

Christianson JP, Ragole T, Amat J, Greenwood BN, Strong PV, Paul ED, Fleshner M, Watkins LR, Maier SF (2010) 5-Hydroxytryptamine 2C receptors in the basolateral amygdala are involved in the expression of anxiety after uncontrollable traumatic stress. Biol Psychiatry 67:339-345. CrossRef Medline

Crowley NA, Bloodgood DW, Hardaway JA, Kendra AM, McCall JG, AlHasani R, McCall NM, Yu W, Schools ZL, Krashes MJ, Lowell BB, Whistler JL, Bruchas MR, Kash TL (2016) Dynorphin controls the gain of an amygdalar anxiety circuit. Cell Rep 14:2774-2783. CrossRef Medline

Dedic N, Kühne C, Jakovcevski M, Hartmann J, Genewsky AJ, Gomes KS, Anderzhanova E, Pöhlmann ML, Chang S, Kolarz A, Vogl AM, Dine J, Metzger MW, Schmid B, Almada RC, Ressler KJ, Wotjak CT, Grinevich V, Chen A, Schmidt MV, et al. (2018) Chronic CRH depletion from GABAergic, long-range projection neurons in the extended amygdala reduces dopamine release and increases anxiety. Nat Neurosci 21:803-807. CrossRef Medline

Fadok JP, Krabbe S, Markovic M, Courtin J, Xu C, Massi L, Botta P, Bylund K, Müller C, Kovacevic A, Tovote P, Lüthi A (2017) A competitive inhibitory circuit for selection of active and passive fear responses. Nature 542: 96-100. CrossRef Medline

Faul F, Erdfelder E, Lang AG, Buchner A (2007) G*Power 3: a flexible statistical power analysis program for the social, behavioral, and biomedical sciences. Behav Res Methods 39:175-191. CrossRef Medline

Gomez JL, Bonaventura J, Lesniak W, Mathews WB, Sysa-Shah P, Rodriguez LA, Ellis RJ, Richie CT, Harvey BK, Dannals RF, Pomper MG, Bonci A, Michaelides M (2017) Chemogenetics revealed: DREADD occupancy and activation via converted clozapine. Science 357:503-507. CrossRef Medline

Gungor NZ, Paré D (2016) Functional heterogeneity in the bed nucleus of the stria terminalis. J Neurosci 36:8038-8049. CrossRef Medline

Kalueff AV, Stewart AM, Song C, Berridge KC, Graybiel AM, Fentress JC (2016) Neurobiology of rodent self-grooming and its value for translational neuroscience. Nat Rev Neurosci 17:45-59. CrossRef Medline

Kash TL, Nobis WP, Matthews RT, Winder DG (2008) Dopamine enhances fast excitatory synaptic transmission in the extended amygdala by a CRFR1-dependent process. J Neurosci 28:13856-13865. CrossRef Medline

Kim J, Zhang X, Muralidhar S, LeBlanc SA, Tonegawa S (2017) Basolateral to central amygdala neural circuits for appetitive behaviors. Neuron 93: 1464-1479.e5. CrossRef Medline

Kim SY, Adhikari A, Lee SY, Marshel JH, Kim CK, Mallory CS, Lo M, Pak S, Mattis J, Lim BK, Malenka RC, Warden MR, Neve R, Tye KM, Deisseroth K (2013) Diverging neural pathways assemble a behavioural state from separable features in anxiety. Nature 496:219-223. CrossRef Medline

Koob GF (1999) Corticotropin-releasing factor, norepinephrine, and stress. Biol Psychiatry 46:1167-1180. CrossRef Medline

Koob GF (2009) Brain stress systems in the amygdala and addiction. Brain Res 1293:61-75. CrossRef Medline

LeDoux JE, Brown R (2017) A higher-order theory of emotional consciousness. Proc Natl Acad Sci U S A 114:E2016-E2025. CrossRef Medline

Lee Y, Davis M (1997) Role of the hippocampus, the bed nucleus of the stria terminalis, and the amygdala in the excitatory effect of corticotropinreleasing hormone on the acoustic startle reflex. J Neurosci 17:64346446. CrossRef Medline

Liang KC, Melia KR, Miserendino MJ, Falls WA, Campeau S, Davis M (1992) Corticotropin-releasing factor: long-lasting facilitation of the acoustic startle reflex. J Neurosci 12:2303-2312. CrossRef Medline

Mahler SV, Vazey EM, Beckley JT, Keistler CR, McGlinchey EM, Kaufling J, Wilson SP, Deisseroth K, Woodward JJ, Aston-Jones G (2014) Designer receptors show role for ventral pallidum input to ventral tegmental area in cocaine seeking. Nat Neurosci 17:577-585. CrossRef Medline

Marcinkiewcz CA, Mazzone CM, D’Agostino G, Halladay LR, Hardaway JA, DiBerto JF, Navarro M, Burnham N, Cristiano C, Dorrier CE, Tipton GJ, Ramakrishnan C, Kozicz T, Deisseroth K, Thiele TE, McElligott ZA, Holmes A, Heisler LK, Kash TL (2016) Serotonin engages an anxiety and fear-promoting circuit in the extended amygdala. Nature 537:97-101. CrossRef Medline

McCall JG, Al-Hasani R, Siuda ER, Hong DY, Norris AJ, Ford CP, Bruchas MR (2015) CRH engagement of the locus coeruleus noradrenergic system mediates stress-induced anxiety. Neuron 87:605-620. CrossRef Medline

Nguyen AQ, Dela Cruz JA, Sun Y, Holmes TC, Xu X (2016) Genetic cell targeting uncovers specific neuronal types and distinct subregions in the bed nucleus of the stria terminalis. J Comp Neurol 524:2379-2399. CrossRef Medline

Nobis WP, Kash TL, Silberman Y, Winder DG (2011) $\beta$-Adrenergic receptors enhance excitatory transmission in the bed nucleus of the stria terminalis through a corticotrophin-releasing factor receptor-dependent and cocaine-regulated mechanism. Biol Psychiatry 69:1083-1090. CrossRef Medline

Normandeau CP, Ventura-Silva AP, Hawken ER, Angelis S, Sjaarda C, Liu X, Pego JM, Dumont EC (2018) A key role for neurotensin in chronicstress-induced anxiety-like behavior in rats. Neuropsychopharmacology 43:285-293. CrossRef Medline

Panksepp J (2011) The basic emotional circuits of mammalian brains: do animals have affective lives? Neurosci Biobehav Rev 35:1791-1804. CrossRef Medline

Paré WP, Glavin GB (1986) Restraint stress in biomedical research: a review. Neurosci Biobehav Rev 10:339-370. CrossRef Medline

Pliota P, Bohm V, Grossl F, Griessner J, Valenti O, Kraitsy K, Kaczanowska J, Pasieka M, Lendl T, Deussing JM, Haubensak W (2018) Stress peptides sensitize fear circuitry to promote passive coping. Mol Psychiatry. Advance online publication. Retrieved June 14, 2018. doi: 10.1038/s41380018-0089-2.

Pomrenze MB, Millan EZ, Hopf FW, Keiflin R, Maiya R, Blasio A, Dadgar J, Kharazia V, De Guglielmo G, Crawford E, Janak PH, George O, Rice KC, Messing RO (2015) A transgenic rat for investigating the anatomy and function of corticotrophin releasing factor circuits. Front Neurosci 9:487. CrossRef Medline

Regev L, Tsoory M, Gil S, Chen A (2012) Site-specific genetic manipulation of amygdala corticotropin-releasing factor reveals its imperative role in mediating behavioral response to challenge. Biol Psychiatry 71:317-326. CrossRef Medline

Sahuque LL, Kullberg EF, McGeehan AJ, Kinder JR, Hicks MP, Blanton MG, Janak PH, Olive MF (2006) Anxiogenic and aversive effects of corticotropin-releasing factor (CRF) in the bed nucleus of the stria terminalis in the rat: role of CRF receptor subtypes. Psychopharmacology (Berl) 186:122-132. CrossRef Medline

Sakanaka M, Shibasaki T, Lederis K (1986) Distribution and efferent projections of corticotropin-releasing factor-like immunoreactivity in the rat amygdaloid complex. Brain Res 382:213-238. CrossRef Medline

Sanford CA, Soden ME, Baird MA, Miller SM, Schulkin J, Palmiter RD, Clark M, Zweifel LS (2017) A central amygdala CRF circuit facilitates learning about weak threats. Neuron 93:164-178. CrossRef Medline

Schindelin J, Arganda-Carreras I, Frise E, Kaynig V, Longair M, Pietzsch T, Preibisch S, Rueden C, Saalfeld S, Schmid B, Tinevez JY, White DJ, Hartenstein V, Eliceiri K, Tomancak P, Cardona A (2012) Fiji: an opensource platform for biological-image analysis. Nat Methods 9:676-682. CrossRef Medline

Schwaber JS, Kapp BS, Higgins GA, Rapp PR (1982) Amygdaloid and basal forebrain direct connections with the nucleus of the solitary tract and the dorsal motor nucleus. J Neurosci 2:1424-1438. CrossRef Medline

Shackman AJ, Fox AS (2016) Contributions of the central extended 
amygdala to fear and anxiety. J Neurosci 36:8050-8063. CrossRef Medline

Silberman Y, Matthews RT, Winder DG (2013) A corticotropin releasing factor pathway for ethanol regulation of the ventral tegmental area in the bed nucleus of the stria terminalis. J Neurosci 33:950-960. CrossRef Medline

Sternson SM, Roth BL (2014) Chemogenetic tools to interrogate brain functions. Annu Rev Neurosci 37:387-407. CrossRef Medline

Sturman O, Germain PL, Bohacek J (2018) Exploratory rearing: a contextand stress-sensitive behavior recorded in the open-field test. Stress 21: 443-452. CrossRef Medline

Swerdlow NR, Geyer MA, Vale WW, Koob GF (1986) Corticotropinreleasing factor potentiates acoustic startle in rats: blockade by chlordiazepoxide. Psychopharmacology 88:147-152. CrossRef Medline

van der Kooy D, Koda LY, McGinty JF, Gerfen CR, Bloom FE (1984) The organization of projections from the cortex, amygdala, and hypothalamus to the nucleus of the solitary tract in rat. J Comp Neurol 224:1-24. CrossRef Medline

Walker DL, Toufexis DJ, Davis M (2003) Role of the bed nucleus of the stria terminalis versus the amygdala in fear, stress, and anxiety. Eur J Pharmacol 463:199-216. CrossRef Medline

Wang XF, Liu JJ, Xia J, Liu J, Mirabella V, Pang ZP (2015) Endogenous glucagon-like peptide-1 suppresses high-fat food intake by reducing synaptic drive onto mesolimbic dopamine neurons. Cell Rep 12:726-733. CrossRef Medline

Yang CF, Chiang MC, Gray DC, Prabhakaran M, Alvarado M, Juntti SA, Unger EK, Wells JA, Shah NM (2013) Sexually dimorphic neurons in the ventromedial hypothalamus govern mating in both sexes and aggression in males. Cell 153:896-909. CrossRef Medline 